\title{
Body length estimation of Neogene macrophagous lamniform sharks (Carcharodon and Otodus) derived from associated fossil dentitions
}

\author{
Victor J. Perez, Ronny M. Leder, and Teddy Badaut
}

\begin{abstract}
The megatooth shark, Otodus megalodon, is widely accepted as the largest macrophagous shark that ever lived; and yet, despite over a century of research, its size is still debated. The great white shark, Carcharodon carcharias, is regarded as the best living ecological analog to the extinct megatooth shark and has been the basis for all body length estimates to date. The most widely accepted and applied method for estimating body size of $O$. megalodon was based upon a linear relationship between tooth crown height and total body length in $C$. carcharias. However, when applying this method to an associated dentition of O. megalodon (UF-VP-311000), the estimates for this single individual ranged from 11.4 to $41.1 \mathrm{~m}$. These widely variable estimates showed a distinct pattern, in which anterior teeth resulted in lower estimates than posterior teeth. Consequently, previous paleoecological analyses based on body size estimates of $O$. megalodon may be subject to misinterpretation. Herein, we describe a novel method based on the summed crown width of associated fossil dentitions, which mitigates the variability associated with different tooth positions. The method assumes direct proportionality between the ratio of summed crown width to body length in ecologically and taxonomically related fossil and modern species. Total body lengths were estimated from 11 individuals, representing five lamniform species: Otodus megalodon, Otodus chubutensis, Carcharodon carcharias, Carcharodon hubbelli, and Carcharodon hastalis. The method was extrapolated for the largest known isolated upper tooth of $O$. megalodon, resulting in a maximum body length estimate of $20 \mathrm{~m}$.
\end{abstract}

Victor J. Perez. Department of Vertebrate Paleontology, Florida Museum of Natural History, 1659 Museum Rd., Gainesville, Florida 32611, USA and Department of Geological Sciences, University of Florida, 241 Williamson Hall, PO Box 112120, Gainesville, Florida 32611, USA and Department of Paleontology, Calvert Marine Museum, Solomons, Maryland 20688, USA Victor.Perez@calvertcountymd.gov Ronny M. Leder. Department of Vertebrate Paleontology, Florida Museum of Natural History, 1659 Museum Rd., Gainesville, Florida 32611, USA and Natural History Museum City of Leipzig, Lortzingstraße

Perez, Victor J., Leder, Ronny M., and Badaut, Teddy. 2021. Body length estimation of Neogene macrophagous lamniform sharks (Carcharodon and Otodus) derived from associated fossil dentitions. Palaeontologia Electronica, 24(1):a09. https://doi.org/10.26879/ 1140

palaeo-electronica.org/content/2021/3284-estimating-lamniform-body-size 
3, 04105 Leipzig, Germany. ronnymaik.leder@leipzig.de

Teddy Badaut. Independent Researcher, Thoirette, France. kieffer_stirlling@hotmail.fr

Keywords: megalodon; body size; fossil; paleoecology; macropredator; apex predator

Submission: 12 November 2020. Acceptance: 1 March 2021.

\section{INTRODUCTION}

The order Lamniformes includes two of the most iconic shark species: the extant great white, Carcharodon carcharias, and the extinct megatooth shark, Otodus megalodon (Cappetta, 1987, 2012). Carcharodon carcharias is the largest macrophagous shark alive today, achieving maximum body lengths of arguably 6 to $7 \mathrm{~m}$ (Gottfried et al., 1996; Castro, 2012; McClain et al., 2015). Otodus megalodon represents the largest macrophagous shark that ever lived, with contentious adult estimates ranging from 10 to more than $30 \mathrm{~m}$ (Dean, 1909; Randall, 1973; Bendix-Almgreen, 1983; Gottfried et al., 1996; Pimiento et al., 2010; Pimiento and Balk, 2015; Reolid and Molina, 2015; Trif et al., 2016; Grant et al., 2017; Razak and Kocsis, 2018; Shimada, 2002a, 2019; Herraiz et al., 2020). This longstanding interest in body size of the world's largest marine macropredators has been shared by professional paleontologists and the public alike. Hypothetical models of Otodus megalodon are used as centerpiece exhibits in numerous natural history museums (e.g., the Calvert Marine Museum, Florida Museum, Smithsonian National Museum of Natural History, Western Australian Museum). Likewise, popular science fiction has featured these taxa, with vastly overestimated body sizes (e.g., Jaws and The Meg). Constraining body size estimates is imperative if we are to accurately represent these taxa and decipher the evolutionary mechanisms that produced these enormous macropredators.

The chondrichthyan fossil record is largely restricted to teeth, due to the high preservation potential of hydroxyapatite and poor preservation potential of cartilage and soft tissue (Kent, 1994). Consequently, interpretation of chondrichthyan evolutionary history is largely restricted to what we can infer from dental data and modern analogs. To estimate the size of Otodus megalodon, a number of researchers have attempted to relate tooth height to total body length in the extant great white shark as a proxy (Gottfried et al., 1996; Pimiento et al., 2010; Pimiento and Balk, 2015; Reolid and Molina, 2015; Trif et al., 2016; Grant et al., 2017; Razak and Kocsis, 2018; Shimada, 2002a, 2019).
Gottfried et al. (1996) estimated body size based on the relationship between total tooth (root and crown) height $(\mathrm{TH})$ of the second upper anterior (A2; see Figure $1 \mathrm{~A}$ for dentition terminology) and total body length (TL), resulting in a conservative maximum adult size of $15.9 \mathrm{~m}$ for $\mathrm{O}$. megalodon. Gottfried et al. (1996) speculated the TL of O. megalodon throughout ontogeny by scaling up TL and body mass in extant Carcharodon carcharias individuals from different ontogenetic stages. Pimiento et al. (2010) used this to define three life stages for O. megalodon: neonate $(\mathrm{TL}<4 \mathrm{~m})$, juvenile $(\mathrm{TL}=4$ to $10.5 \mathrm{~m}$ ), and adult ( $\mathrm{TL}>10.5 \mathrm{~m}$ ).

Shimada (2002a, 2019) suggested that growth rates in the crown and root are not isometric, and instead developed a method based on crown height $(\mathrm{CH})$. Shimada (2002a) used a linear regression to determine the relationship between $\mathrm{CH}$ and TL for each tooth position in C. carcharias. It was then proposed that these equations may be an appropriate analog to estimate body size of $O$. megalodon, given that $C$. carcharias represents the largest extant macrophagous shark. All subsequent studies (Pimiento et al., 2010; Pimiento and Balk, 2015; Reolid and Molina, 2015; Trif et al., 2016; Grant et al., 2017; Razak and Kocsis, 2018; Herraiz et al., 2020) mentioned have since used the Shimada (2002a) equations to estimate the size of $\mathrm{O}$. megalodon. However, K-12 students applied Shimada's (2002a) equations to a 3D printed model of an associated dentition (i.e., multiple teeth from a single individual) of $O$. megalodon (UF-VP-311000), resulting in a range of body length estimates from 12 to $45 \mathrm{~m}$ for this single individual (Grant et al., 2017). This prompted the authors of this study to re-evaluate the Shimada (2002a) method and to develop the novel method described herein.

Since then, Shimada (2019) also re-evaluated the original linear equations proposed in 2002 and took a closer look at the relationship between $\mathrm{CH}$ and TL of anterior tooth positions in Carcharodon carcharias. In this study, Shimada determined that a power function results in a greater correlation between $\mathrm{CH}$ and $\mathrm{TL}$ than a linear regression. Further, Shimada determined that upper anterior teeth 
A Upper Left Upper Right
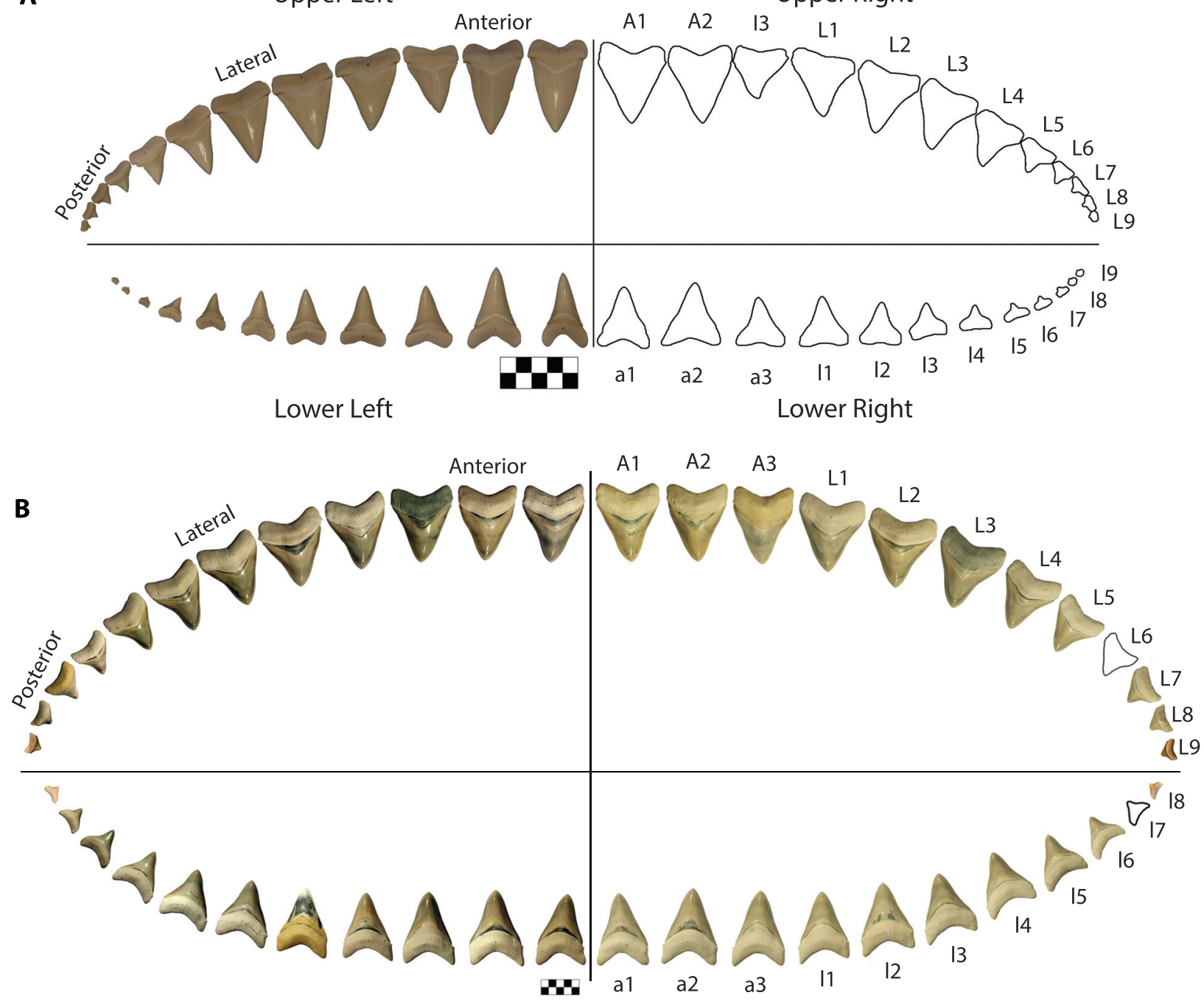

C
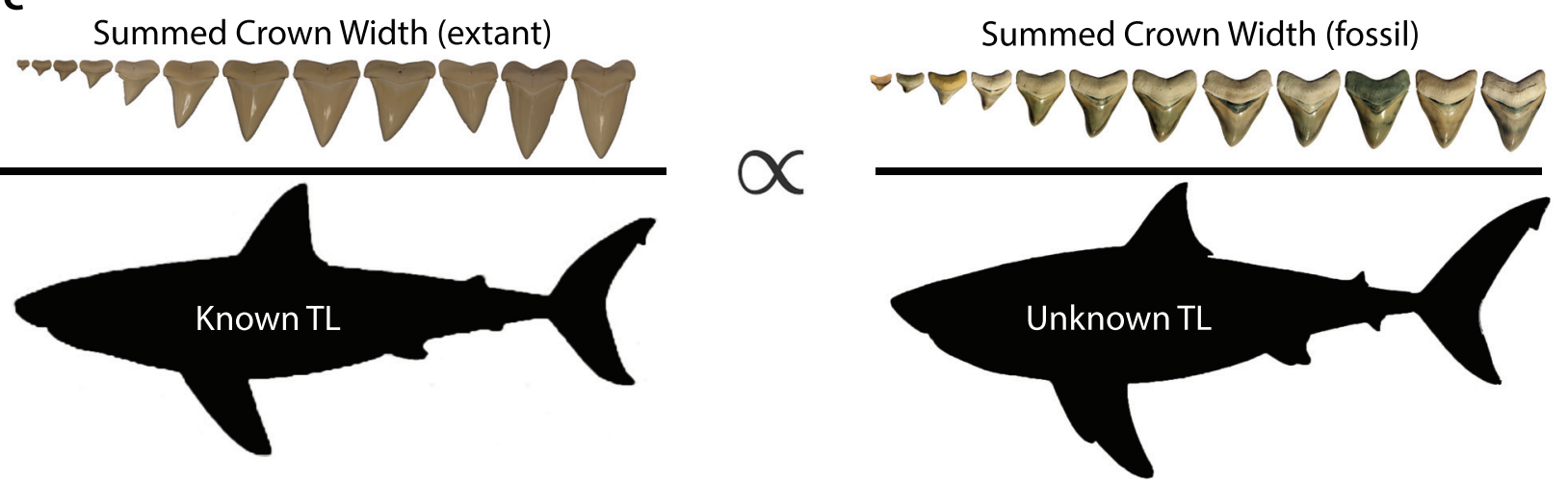

FIGURE 1. Premise of summed crown width method. (A) Carcharodon carcharias dentition in lingual view, with applicable terminology. The right half is an illustration of the typical dental formula for $C$. carcharias. The left half is from a $5.18 \mathrm{~m}$ female with one less posterior tooth in the lower tooth series (originally figured in Hubbell, 1996; figure 5). Scale bar equals $5 \mathrm{~cm}$. (B) The most complete known associated dentition of Otodus megalodon (CH-31-46P) in lingual view. Scale bar equals $5 \mathrm{~cm}$. (C) Body length of fossil taxa is calculated under the assumption that the ratio of summed crown width to total body length (TL) is proportional in ecologically and taxonomically related species. Silhouette proportions for O. megalodon are based on Cooper et al. (2020). A/a = anterior, I = intermediate, and L/I = lateral. Uppercase letters denote upper teeth and lowercase letters denote lower teeth. 
resulted in more reliable estimates than lower teeth, and that the second upper anterior (A2) tooth position provides more reliable estimates than the first upper anterior (A1) tooth position. Shimada et al. (2020) analyzed dental homology in macrophagous lamniforms based on the typical "lamnoid tooth pattern." In this dental pattern, anterior teeth are always the tallest (Applegate, 1965; Shimada, 2020). Shimada (2019) used the isolated $O$. megalodon tooth with the largest $\mathrm{CH}$ in a museum collection (NSM PV-19896; $\mathrm{CH}=120 \mathrm{~mm}$ ) to estimate a maximum body size, assuming it represents tooth position $\mathrm{A} 1-\mathrm{A} 2$, resulting in a $\mathrm{TL}$ of 14.2 to $15.3 \mathrm{~m}$.

These results have clear implications that applying the Shimada (2002a) method to a sample of isolated teeth could be biased by estimates derived from different tooth positions. Whether one attempts to apply the Shimada (2002a) or Shimada (2019) method to estimate body size, both require identification, or at least approximation, of tooth positions from isolated fossil teeth. Identifying tooth positions requires knowledge of a taxon's dental formula, which defines the total number of teeth and how they are arranged within a dentition. Two forms of evidence have been used to infer the dental formula of the megatooth lineage, each of which has pros and cons. Extant macrophagous sharks offer a source of indirect evidence, in which the dental formula of the extinct megatooth lineage is assumed to reflect that of the closest living analogs (i.e., the lamnoid tooth pattern). The fossil record offers the only direct evidence of the megatooth lineage but consists primarily of isolated teeth (Cappetta, 2012). Rare disarticulated, associated dentitions represent the most holistic direct evidence available to reconstruct the dental formula of the extinct megatooth lineage (Uyeno et al., 1989; Purdy et al., 2001; Pimiento et al., 2010; Perez et al., 2019). Consequently, all reconstructions of the dental formula in the megatooth lineage represent hypothetical models (Welton and Farish, 1993; Shimada, 2005). The various dental models proposed are fundamentally important for understanding potential biases in body length estimates of the megatooth lineage. Proposed dental models for the megatooth lineage are intrinsically linked to their taxonomic assignment.

\section{Megatooth Shark Taxonomy}

The taxonomy of Otodus megalodon has changed frequently and even now a complete consensus has not been reached. Otodus megalodon was originally assigned to the genus Carcharodon, under the assumption that it was related to Carcharodon carcharias, and was placed in the family Lamnidae (Agassiz, 1833-1844; Applegate and Espinosa-Arrubarrena, 1996; Gottfried et al., 1996; Purdy, 1996; Purdy et al., 2001). Other researchers have proposed that $O$. megalodon evolved as a separate lineage derived from Otodus obliquus, placing it in the family Otodontidae (Casier, 1960; Glickman, 1964; Zhelezko and Kozlov, 1999; Ward and Bonavia, 2001; Nyberg et al., 2006; Cappetta, 2012; Ehret et al., 2012; Shimada et al., 2017; Perez et al., 2019). Three alternative generic names had been proposed: Carcharocles (Jordan and Hannibal, 1923), Procarcharodon (Casier, 1960), and Megaselachus (Glickman, 1964). Consequently, many researchers began to use the genus Carcharocles, given that it had precedence over Procarcharodon and Megaselachus, to describe all serrated taxa within the megatooth lineage (i.e., C. auriculatus, $C$. angustidens, C. chubutensis, and C. megalodon).

The presence of serrations represents a convenient and easily distinguishable character to delineate $O$. obliquus from its descendants; however, Cappetta (2012) argued that serrations were not a sufficient character to warrant a separate genus and instead used Otodus for the entire lineage. As somewhat of a compromise, Cappetta (2012) proposed the use of Carcharocles and Megaselachus as subgenera to describe serrated taxa within the megatooth lineage. Shimada et al. (2017) also argued for the use of Otodus for the entire megatooth lineage to achieve monophyly, under the assumption that Parotodus and Megalolamna were sister taxa to Otodus within the family Otodontidae. However, Shimada et al. (2017) acknowledged that this shifts the issue of paraphyly to the ancestor of O. obliquus, Cretalamna, and that paraphyletic taxa are inevitable when attempting to place Linnaean taxa onto a phylogenetic tree.

Kent (2018) noted that the debate between the use of Carcharocles versus Otodus hinges on whether the lineage evolved through cladogenesis versus anagenesis and argued that the fossil record of megatooth sharks may not be sufficiently detailed to demonstrate anagenesis. Whether the megatooth lineage evolved through a series of rapid branching events (i.e., cladogenesis) or through the slow accumulation of mutations over time (i.e., anagenesis) is somewhat irrelevant to this study. For now, we will adopt the popular use of Otodus to describe the megatooth sharks as a chronospecific lineage. Rather, what is relevant is 


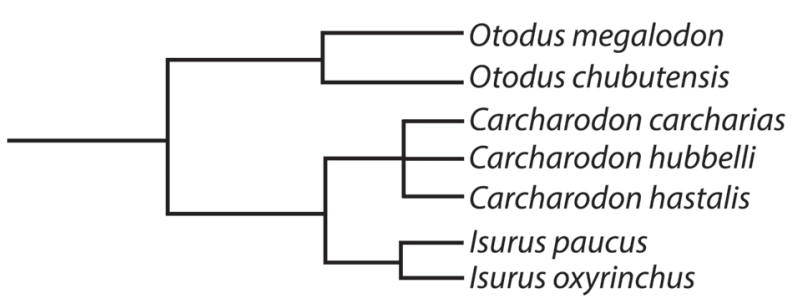

FIGURE 2. Phylogeny of macrophagous lamniforms included in this study, showing the relationship between the family Otodontidae (O. megalodon and O. chubutensis) and the family Lamnidae (C. carcharias, C. hubbelli, C. hastalis, I. paucus, and I. oxyrinchus).

that we agree that $O$. megalodon evolved from $O$. obliquus and represents a separate lineage from that of C. carcharias (Figure 2).

\section{The Megatooth Dental Formula}

Lamniform sharks typically exhibit heterodonty known as the "lamnoid tooth pattern," which consists of both monognathic and dignathic heterodonty (Shimada, 2002b; Shimada et al., 2020). In macrophagous lamniforms, upper monognathic heterodonty is generally characterized by two rows of anterior teeth on either side of the jaw symphysis, followed by one or more intermediate tooth rows, and a series of lateral teeth. The anterior teeth are vertically erect and generally represent the tallest teeth in the dentition. The intermediate teeth are significantly smaller, interrupting the general pattern of the tallest teeth being mesial positions and smallest teeth being distal positions, relative to the jaw symphysis. Shimada (2002b) referred to the first three tooth positions (i.e., A1, A2, and I1) as "index tooth rows" to identify dental homologies. However, it is possible for a shark to modify their dentition by either losing or gaining a tooth row. Further, there is intraspecific variability in the lamnoid tooth pattern (Hubbell, 1996).

Applegate and Espinosa-Arrubarrena (1996; figure 1a) depicted C. carcharias with 46 teeth in its functional series. In this model, a complete half of the dentition has an upper tooth series with two anterior, one intermediate, five lateral, and four posterior teeth and a lower tooth series with three anterior, five lateral, and three posterior teeth. In Shimada (2002a; figure 1), Carcharodon carcharias has a functional series consisting of 50 teeth. In this model, a complete half of the dentition has an upper tooth series with two anterior, one intermediate, and 10 latero-posterior teeth and a lower tooth series with two anterior, one intermediate, and nine latero-posterior teeth. Based on denti- tions observed by the authors of this study, we assume that the typical dental formula for $C$. carcharias is in between both models, with 48 teeth in the first functional series (Figure 1A).

Shimada (2005) defined a spectrum of preservation states for fossil shark teeth, ranging from common isolated teeth to rare associated dentitions. Isolated tooth sets (i.e., composite or artificial dentitions) are comprised of teeth from multiple individuals from the same taxon and represent a completely fabricated dental model. Associated tooth sets (i.e., associated dentitions) represent multiple teeth belonging to a single individual, which can be found either in articulation or disarticulated. Articulated dentitions provide a true dental model. Disarticulated dentitions require inferences to reassemble the true dental model but provide context for making those inferences. Six disarticulated, associated dentitions of $O$. chubutensis and O. megalodon have been referenced in peer-reviewed literature (Uyeno et al., 1989; Purdy et al., 2001; Pimiento et al., 2010; Grant et al., 2017; Perez et al., 2019). To date, no one has reported a verified articulated, associated dentition of $O$. chubutensis or $O$. megalodon.

Applegate and Espinosa-Arrubarrena (1996) created artificial dentitions of Otodus/Carcharodon using isolated tooth sets, in which they proposed a dental formula for O. megalodon comprised of 58 teeth in the functional series. In this model, a complete half of the dentition consisted of an upper functional series with two anterior, one intermediate, seven lateral, and four posterior teeth and a lower functional series with three anterior, eight lateral, and four posterior teeth. Purdy et al. (2001) figured partial reconstructions of two disarticulated, associated dentitions of Otodus chubutensis (USNM 411881 and USNM 299832) and one disarticulated, associated dentition of Otodus megalodon (NCSM 13073) from the Lee Creek Mine in Aurora, North Carolina. These reconstructions all included a medially-oriented upper intermediate tooth, based on an assumed evolutionary relationship with Carcharodon carcharias.

Pimiento et al. (2010; figure S1) provided a dental model for Otodus megalodon consisting of 46 teeth in its functional series, with a complete half of the dentition comprised of an upper functional series with three anterior and nine lateroposterior teeth and a lower functional series with three anterior and eight latero-posterior teeth. This was the first dental model for Otodus megalodon that lacked any intermediate tooth positions. It is unclear if tooth position A3 in O. megalodon should 
be considered an intermediate tooth, but the proportions are certainly not analogous to 11 in $C$. carcharias (Figure 1). Pimiento et al. (2010) stated that this dental model was adapted from Gottfried et al. (1996), which presumably refers to the composite, artificial dentition of 0 . megalodon on exhibit at the Calvert Marine Museum (see Gottfried et al., 1996; figure 1B). Gottfried et al. (1996) stated that the figured O. megalodon dentition was casted from the original Smithsonian composite dentition "... prior to the discovery of important natural tooth sets at Lee Creek Mine, North Carolina and in Florida that help clarify the arrangement of teeth in C. megalodon."

The dental model for Otodus megalodon in Pimiento et al. (2010; figure S1) originated, at least in part, from dental reconstructions based on the fossil associated dentitions that Gottfried et al. (1996) had alluded to. Pimiento et al. (2010; tables S1 and S2) referred to these specimens as "juvenile Carcharocles megalodon associated tooth set" and "adult Carcharocles megalodon associated tooth set" and reported crown height $(\mathrm{CH})$ and crown width (CW) measurements for each tooth position. The juvenile individual was recovered by L. Martin and G. Hubbell in 1995 from the Bone Valley region in Florida (herein referred to as $\mathrm{CH}$ 31-46P, Figure 1B), and the adult individual was recovered by $A$. Felt in 1996 from the Lee Creek Mine in North Carolina (herein referred to as UFVP-311000). Both disarticulated, associated dentitions were originally reconstructed by $\mathrm{G}$. Hubbell. Images of $\mathrm{CH}-31-46 \mathrm{P}$ can be found on www.elasmo.com (Bourdon, 2005; Razak and Kocsis, 2018), and a 3D model of UF-VP-311000 is figured in Grant et al. (2017; figure 1). The Bone Valley dentition ( $\mathrm{CH}-31-46 \mathrm{P})$ has been referenced in exhibits at the Florida Museum, Smithsonian National Museum of Natural History, and Western Australian Museum.

Pimiento et al. (2010; figure 4) used the $\mathrm{CH}: \mathrm{CW}$ ratio in these associated dentitions to approximate tooth positions of isolated $\mathrm{O}$. megalodon teeth from the Gatun Formation. Some teeth were assigned to an exact tooth position, while others were given a range of potential tooth positions. Pimiento et al. (2010) then used these tooth positions to estimate body size with the equations reported by Shimada (2002a) and determined that the Gatun Formation represented a paleo-nursery for O. megalodon. Pimiento and Balk (2015) repeated this process to analyze spatial and temporal macroevolutionary body size trends in $O$. megalodon. This method has since propagated into numerous studies of 0 . megalodon (Reolid and Molina, 2015; Trif et al., 2016; Grant et al., 2017; Razak and Kocsis, 2018; Herraiz et al., 2020).

Given that fossil associated dentitions were influential in predicting the dental formula for Otodus megalodon, it seems logical that we should test the accuracy of body length estimates using these associated dentitions as hypothetical models. Further, preliminary results reported in Grant et al. (2017) indicated that the Shimada (2002a) method results in highly variable body length estimates. As such, this study analyzes variability in body length estimates by applying the dental model proposed by Pimiento et al. (2010) to fossil associated dentitions. In addition, a novel method for estimating TL is proposed based on this dental model.

\section{Body Length Estimation using Jaw Width}

Methods for estimating body length based on $\mathrm{TH}, \mathrm{CH}$, and $\mathrm{CW}$ all follow a similar rationalization that teeth grow proportionately with total body length. Reolid and Molina (2015; figure 4) compared the linear relationship between different crown measurements in the second upper anterior tooth position (A2) and total body length (TL) in Carcharodon carcharias, reporting a greater correlation for $\mathrm{CH}$ than $\mathrm{CW}$ ( $r=0.92$ for $\mathrm{CH}$ and $\mathrm{r}=0.53$ for $\mathrm{CW}$ ). However, after re-calculating the Pearson coefficient of correlation ( $r$ ) from the Reolid and Molina (2015) dataset, the correlation should be $r=0.77$ for $\mathrm{CW}(n=58)$ and $r=0.93$ for $\mathrm{CH}(n=85)$. While this still indicates that $\mathrm{CH}$ is a better predictor of body length than $\mathrm{CW}$, it does not consider other tooth positions or summed crown width (SCW) of associated teeth as a proxy for body length. In addition, there has been inconsistency in the literature regarding tooth position nomenclature. Hubbell (1996) referred to the first two anterior teeth of $C$. carcharias as $A 2$ and $A 3$, due to a hypothesis from Applegate and Espinosa-Arrubarrena (1996) that $C$. carcharias had lost an anterior tooth row during its evolution. Consequently, Reolid and Molina (2015) included data from Hubbell (1996) that actually refers to tooth position A1 and combined this with data from other studies for tooth position A2.

Lowry et al. (2009) studied the relationship between jaw circumference and total body length in 14 shark species, as a means of estimating body size from shark bite marks. This forensic method allows researchers to estimate the body size of individuals involved in shark attacks. Lowry et al. 
TABLE 1. Specimen data for fossil material included in this study.

\begin{tabular}{lllll}
\hline \multicolumn{1}{c}{ Specimen ID } & \multicolumn{1}{c}{ Location } & Lithostratigraphy & Geologic Age & Nature of Specimen \\
\hline $\begin{array}{l}\text { Otodus megalodon } \\
\text { UF-VP-311000 }\end{array}$ & North Carolina, USA & Yorktown Fm & Pliocene & 37 associated teeth \\
GHC 1 & Atacama Desert, Chile & Bahía Inglesa Fm & Miocene & 92 associated teeth \\
CH-31-46P & Florida, USA & Bone Valley Fm & Miocene & 95 associated teeth \\
UF-VP-460000 & Atacama Desert, Chile & Bahía Inglesa Fm & Miocene & 43 associated teeth \\
GHC 6 & South Carolina, USA & Hawthorn Group & Miocene & 1 isolated tooth \\
Otodus chubutensis & North Carolina, USA & Pungo River Fm & Miocene & 106 associated teeth \\
USNM 411881 & North Carolina, USA & Pungo River Fm & Miocene & 32 associated teeth \\
USNM 299832 & Ica, Peru & Caballos Fm & Miocene & 65 associated teeth \\
GHC 3 & Ica, Peru & Caballos Fm & Miocene & 53 associated teeth \\
UF-VP-312864 & & & \\
$\begin{array}{l}\text { Carcharodon carcharias } \\
\text { GHC 4 }\end{array}$ & Sacaco, Peru & Pisco Fm & Mio-Pliocene & 65 associated teeth \\
$\begin{array}{l}\text { Carcharodon hubbelli } \\
\text { UF-VP-226255 }\end{array}$ & Sacaco, Peru & Pisco Fm & Miocene & Articulated skeleton: 222 \\
Carcharodon hastalis & & & & teeth, 45 centra \\
GHC 5 & Sacaco, Peru & Pisco Fm & Mio-Pliocene & 165 associated teeth \\
\hline
\end{tabular}

(2009) used a metric referred to as the interdental distance (IDD), which is measured as the distance between the crown apex of two neighboring teeth, as a proxy for jaw circumference. A linear regression of IDD versus TL for $C$. carcharias resulted in an $R^{2}=0.98$ for the upper jaw and $R^{2}=0.97$ for the lower jaw. Siversson (2012) first emphasized the potential of applying this method to estimate body size in fossil taxa, specifically the extinct Cretaceous lamniform Cardabiodon ricki. Newbrey et al. (2015) applied the jaw circumference method to a partially articulated, associated dentition of $C$. ricki, resulting in a body length estimate of $5.5 \mathrm{~m}$. This method has a strong foundational premise but does not offer a way to account for missing teeth in fossil dentitions and requires assumptions regarding interdental spacing.

This study introduces a novel method for estimating body size in fossil lamniform sharks that builds on the concept that jaw circumference is proportional to total body length. Such that, the summed crown width (SCW) in the functional series is constrained by jaw size. Based on a simple mathematical concept referred to as the rule of three, this method assumes direct proportionality between the ratio of SCW to TL in related modern and fossil taxa (Figure 1C). Herein, we apply this method to fossil associated dentitions from five macrophagous lamniform species within the families Otodontidae and Lamnidae: Otodus megal- odon, Otodus chubutensis, Carcharodon carcharias, Carcharodon hubbelli, and Carcharodon hastalis.

\section{MATERIALS AND METHODS}

\section{Modern and Fossil Dentitions}

Data was collected from the first functional series in 11 fossil associated dentitions of lamniform sharks (Table 1) and 19 modern lamniform dentitions (Table 2). These specimens are reposited in the Florida Museum (UF-VP), Gordon Hubbell Collection (GHC), and the National Museum of Natural History of the Smithsonian Institution (USNM). Specimens in the GHC are gradually being acquisitioned into the Florida Museum vertebrate paleontology collection and will remain accessible for research throughout the process. Provenance information for these specimens was derived from each museum's collections database and/or personal communication with the museum's respective collections manager (i.e., R. Hulbert, G. Hubbell, and D. Bohaska).

Four associated dentitions and a single isolated tooth of Otodus megalodon were included in this study. UF-VP-311000 consists of 37 teeth (22 from the first functional series) collected by A. Felt in 1996 within the Nutrien Corp phosphate mine (commonly known as the Lee Creek Mine) in Aurora, North Carolina (Figure 3A). 3-D files of UF- 
TABLE 2. Specimen data for 19 modern dentitions. SCW = summed crown width. TL = total body length. Measurements are separated for the different regions preserved: upper left (UL), upper right (UR), lower left (LL), and lower right (LR).

\begin{tabular}{|c|c|c|c|c|c|c|c|}
\hline \multirow[b]{2}{*}{ Specimen ID } & \multirow[b]{2}{*}{ Location } & \multirow[b]{2}{*}{ Sex } & \multicolumn{4}{|c|}{ SCW (mm) } & \multirow[b]{2}{*}{$\mathrm{TL}(\mathrm{cm})$} \\
\hline & & & UL & UR & LL & LR & \\
\hline \multicolumn{8}{|l|}{ Carcharodon carcharias } \\
\hline SOP020105018.011 & Unknown & $M$ & 152.99 & - & 98.39 & - & 237 \\
\hline F7687 & Albany, Australia & $\mathrm{F}$ & 319.99 & - & 195.3 & - & 518 \\
\hline C41185 & Ponce de Leon Inlet, FL & $\mathrm{F}$ & 191.21 & 195.1 & 131.95 & 129.11 & 281 \\
\hline R92185 & Pointe Vicente, CA & $\mathrm{F}$ & 370.35 & 355.8 & 224.9 & 234.85 & 536 \\
\hline L11685 & Anacapa Island, CA & $F$ & 361.34 & 363.78 & 231.5 & 231.46 & 563 \\
\hline SP1394 & St. Petersburg, FL & M & 337.47 & 344.3 & 223.96 & 226.9 & 474 \\
\hline F102281 & Albany, Australia & $\mathrm{F}$ & 152.48 & 170.82 & 107.27 & 109.77 & 244 \\
\hline Car206 & Los Angeles, CA & $M$ & 84.66 & 79.94 & 55.99 & 55.27 & 124 \\
\hline RC112885 & Los Angeles, CA & $\mathrm{F}$ & 115.04 & 113.89 & 82.23 & 79.68 & 170 \\
\hline H5384 & Ledge Point, Australia & $\mathrm{F}$ & 323.76 & 320.52 & 193.48 & 197.19 & 594 \\
\hline H10886 & Key Largo, FL & M & 274.32 & 277.66 & 186.02 & 183.56 & 503 \\
\hline Hubbell (1996, fig. 2) & Unknown & M & - & 291.72 & - & 190.45 & 440 \\
\hline Hubbell (1996, fig. 4) & Unknown & $?$ & - & 218.35 & - & 136.67 & 366 \\
\hline Hubbell (1996, fig. 5) & Unknown & $\mathrm{F}$ & - & 316.509 & - & 191.89 & 518 \\
\hline Hubbell (1996, fig. 6) & Unknown & M & - & 298.15 & - & 182.83 & 488 \\
\hline H8993 & Bunbury, Australia & $\mathrm{M}$ & - & 311.73 & - & 189.36 & 518 \\
\hline GHC 7 & Unknown & $\mathrm{M}$ & - & 314.78 & - & 195.92 & 520 \\
\hline \multicolumn{8}{|l|}{ Isurus oxyrinchus } \\
\hline GHC 8 & San Nicol's Island, CA & $\mathrm{F}$ & 187.24 & 182.11 & 155.15 & 157.7 & 320 \\
\hline \multicolumn{8}{|l|}{ Isurus paucus } \\
\hline GHC 9 & Pompano Beach, FL & $\mathrm{F}$ & 238.48 & 249.82 & 215.9 & 207.32 & 488 \\
\hline
\end{tabular}

VP-311000 are freely available on MorphoSource.org. GHC 1 consists of 92 teeth (36 from the first functional series) found by $M$. Marinelarena in 2003 within the phosphate mining region of the Atacama Desert in northern Chile (Figure 3B). $\mathrm{CH}-31-46 \mathrm{P}$ consists of 95 teeth (44 teeth from the first functional series) found by $L$. Martin and $G$. Hubbell in 1995 within the Four Corners phosphate mine in Polk County, Florida (Figure $1 \mathrm{~B}$ and $3 \mathrm{C}$ ). The physical specimen resides in the $\mathrm{GHC}$; although, reproductions can be purchased from Bone Clones under the code $\mathrm{CH}-31-46 \mathrm{P}$ (we use this as a temporary identifier until the specimen is assigned a globally unique identifier). UF-VP460000 consists of 43 teeth (30 from the first functional series) found by J. Arias in 2003 within the phosphate mining region of the Atacama Desert in northern Chile (Figure 3D). GHC 6 represents the largest isolated tooth of 0 . megalodon known to the authors of this study ( $\mathrm{TH}=165 \mathrm{~mm}, \mathrm{CH}=122$ $\mathrm{mm}, \mathrm{CW}=133 \mathrm{~mm}$ ). This specimen was found by $\mathrm{V}$.
Bertucci while diving in the Morgan River in South Carolina.

Four associated dentitions of Otodus chubutensis were included in this study. USNM 411881 consists of 106 teeth (38 from the first functional series) found by P. Harmatuk in 1986 within the Nutrien Corp phosphate mine in Aurora, North Carolina (Figure 4A). USNM 299832 consists of 32 teeth (20 from the first functional series) found by P. Harmatuk in 1981 within the Nutrien Corp phosphate mine in Aurora, North Carolina (Figure 4B). GHC 3 consists of 65 teeth (31 from the first functional series) found by $\mathrm{G}$. Hubbell in 1993 on the western bank of the Ica River in Peru (Figure 4C). UF-VP-312864 consists of 53 teeth (35 from the first functional series) collected in 2002 from the Ica River in Peru (Figure 4D).

Three associated dentitions of Carcharodon spp. were included in this study, all from Sacaco, Peru. GHC 4 is a C. carcharias dentition consisting of 65 associated teeth (32 from the first functional series) collected by C. Martin in 1988 (Figure 5A). 

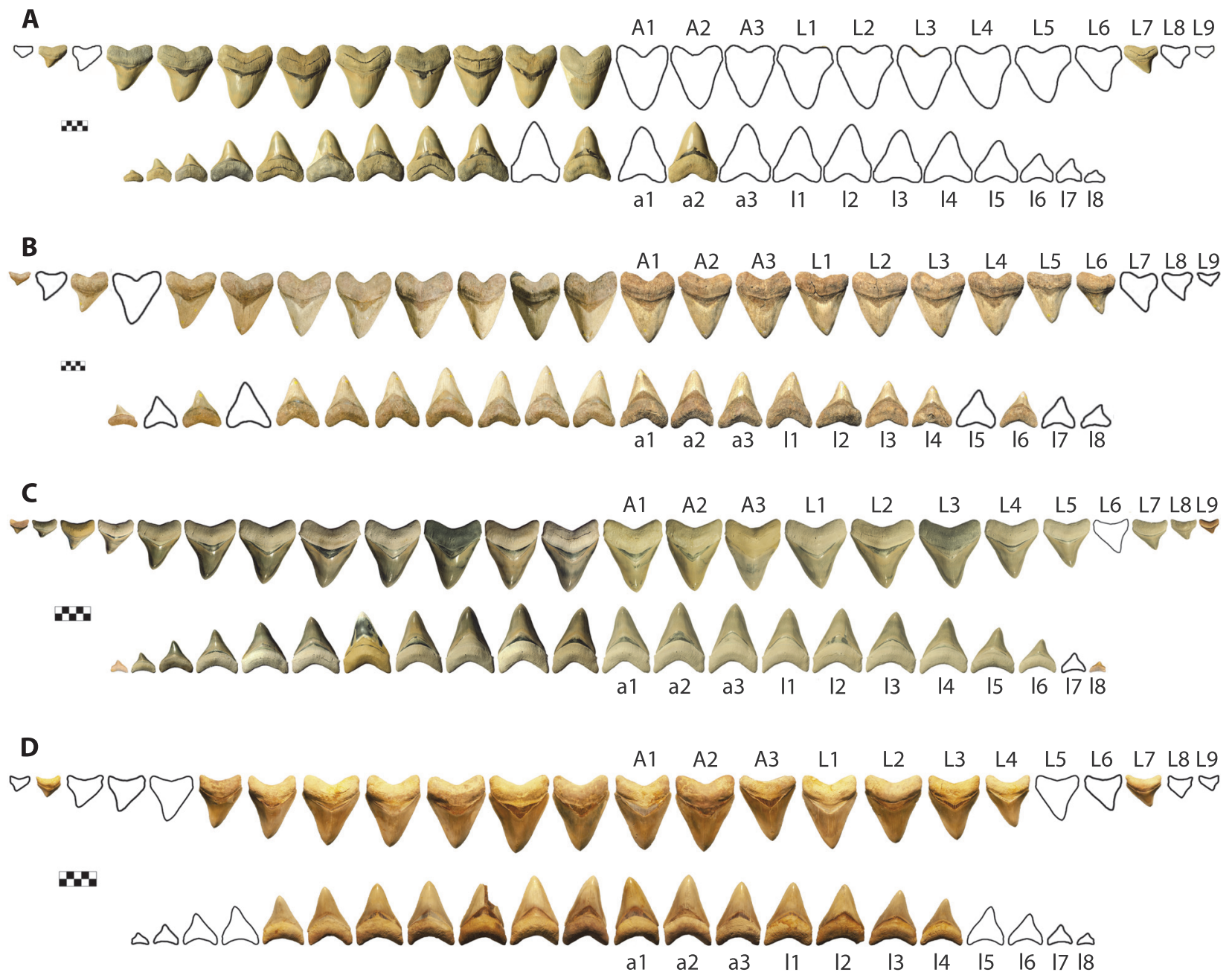

FIGURE 3. Associated dentitions of Otodus megalodon in lingual view. (A) UF-VP-311000; (B) GHC 1; (C) CH-3146P; and (D) UF-VP-460000. Scale bars equal $5 \mathrm{~cm}$.

GHC 5 is a C. hastalis dentition consisting of 165 teeth (40 from the first functional series) collected by C. Martin in 1988 (Figure 5B). UF-VP-226255 is a partially articulated skeleton of $C$. hubbelli consisting of 222 teeth, 45 centra, and portions of the cartilaginous mandibular arch and neurocranium (see Ehret et al., 2009, 2012).

To date, no completely articulated dentitions of $O$. megalodon nor $O$. chubutensis have been reported. Consequently, reconstructions of the fossil dentitions represent hypothetical models that can only be verified by the discovery of fully articulated dentitions of each species being analyzed. As such, the dental patterns utilized reflect a major assumption that is fundamental to the body length method described in this study.

Among the 19 modern lamniform dentitions, measurements were recorded from 17 Carcharodon carcharias individuals, one Isurus oxyrinchus individual, and one Isurus paucus individual. All modern specimens originated from the GHC collection. Specimens that were physically available were measured using calipers, whereas specimens that were figured in Hubbell (1996) were measured digitally using ImageJ. See Table 2 for additional specimen information.

\section{Dental Measurements}

Crown width $(\mathrm{CW})$ and crown height $(\mathrm{CH})$ were measured for every tooth position in the 19 modern dentitions (Appendices 1 and 2) and 11 fossil dentitions (Appendices 3 and 4). CW is defined as a line segment between the crown-root contact on the mesial and distal cutting edges. $\mathrm{CH}$ is defined as a perpendicular line segment from the crown apex to the CW line segment. For nine of the 19 modern analogs, authors VJP and RML independently measured $\mathrm{CH}$ and $\mathrm{CW}$. These measure- 

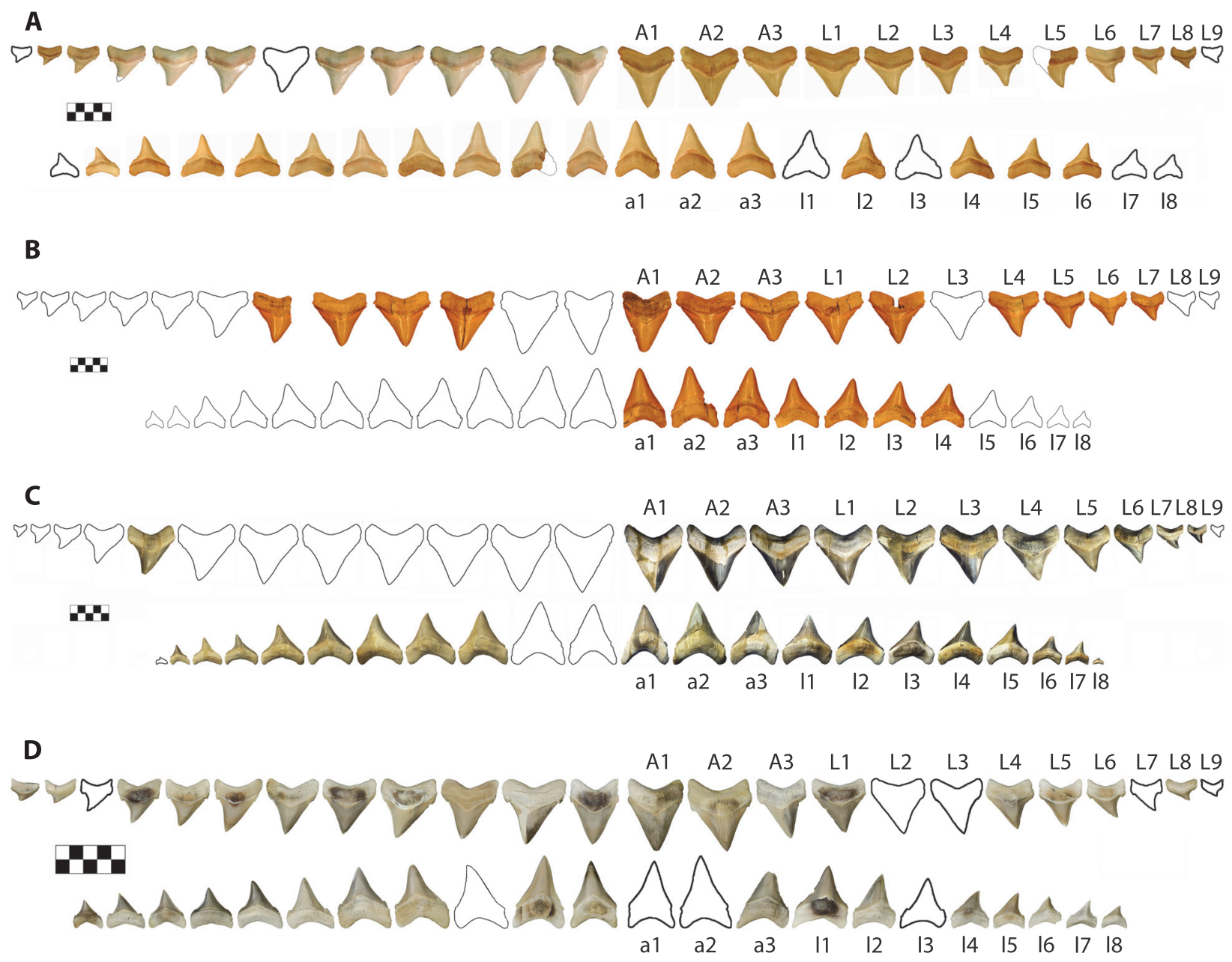

FIGURE 4. Associated dentitions of Otodus chubutensis in lingual view. (A) USNM 411881 (adapted from Perez et al., 2019; fig. 5); (B) USNM 299832; (C) GHC 3; and (D) UF-VP-312864. Scale bars equal $5 \mathrm{~cm}$.

ments were used to address how much variation in the final body length estimate could be attributed to human measurement error.

Dentitions were segmented into four regions (upper left, upper right, lower left, and lower right). Summed crown width was measured for each region of the dentitions. The summed crown width of all teeth present in the dentition is referred to as $\mathrm{SCW}_{\mathrm{ms}}$. To account for missing teeth in the fossil dentitions, correction factors (CF) were determined by calculating the percent of the total summed width attributable to each tooth position in the modern and fossil dentitions (Figure 6 and Appendix 5). The mean percentage for each tooth position of modern Carcharodon carcharias was applied as a correction factor to estimate the width of missing teeth in the fossil dentitions of Carcharodon spp.
Missing teeth in the Otodus spp. dentitions were corrected using percentages from the most complete, comparable fossil Otodus dentition (Appendix 5). Corrected summed crown width $\left(\mathrm{SCW}_{\mathrm{c}}\right)$ is calculated to account for missing teeth by dividing the measured summed crown width $\left(\mathrm{SCW}_{\mathrm{ms}}\right)$ by one minus the sum of all correction factors (Eq. 1). Summed crown width, measured and corrected, are provided in Table 3 for all fossil dentitions.

$$
S C W_{c}=\frac{S C W_{m s}}{\left[1-\sum(C F)\right]}
$$

Eq. 1

\section{Body Length Estimation}

Body length estimates were calculated under a basic assumption that the ratios of summed 

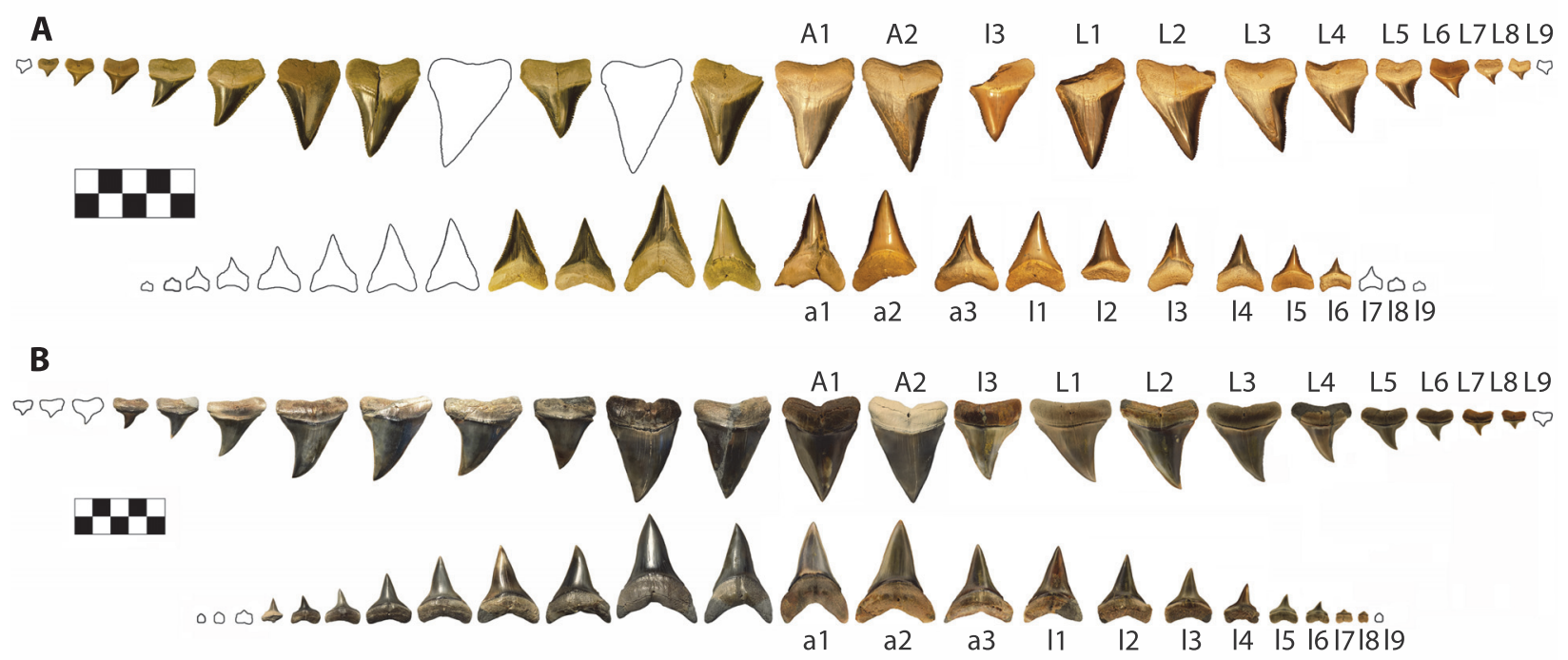

FIGURE 5. Associated dentitions of Carcharodon spp. in lingual view. (A) Carcharodon carcharias, GHC 4. (B) Carcharodon hastalis, GHC 5. Scale bars equal $5 \mathrm{~cm}$. See Ehret et al. (2009) for images of the Carcharodon hubbelli dentition, UF-VP-226255.

crown width (SCW) to body length (TL) are proportional in taxonomically and ecologically related species (Eq 2). The rule of three method assumes direct proportionality between the ratio of summed crown width $\left(a=\mathrm{SCW}_{\mathrm{m}}\right)$ to body length $\left(b=\mathrm{TL}_{\mathrm{m}}\right)$ in modern taxa (e.g., C. carcharias, I. oxyrinchus, and $I$. paucus) and the ratio of summed crown width $\left(c=\mathrm{SCW}_{\mathrm{f}}\right)$ to body length $\left(x=\mathrm{TL}_{\mathrm{f}}\right)$ in fossil taxa (e.g., O. megalodon, O. chubutensis, C. carcharias, C. hubbelli, and C. hastalis). Such that,
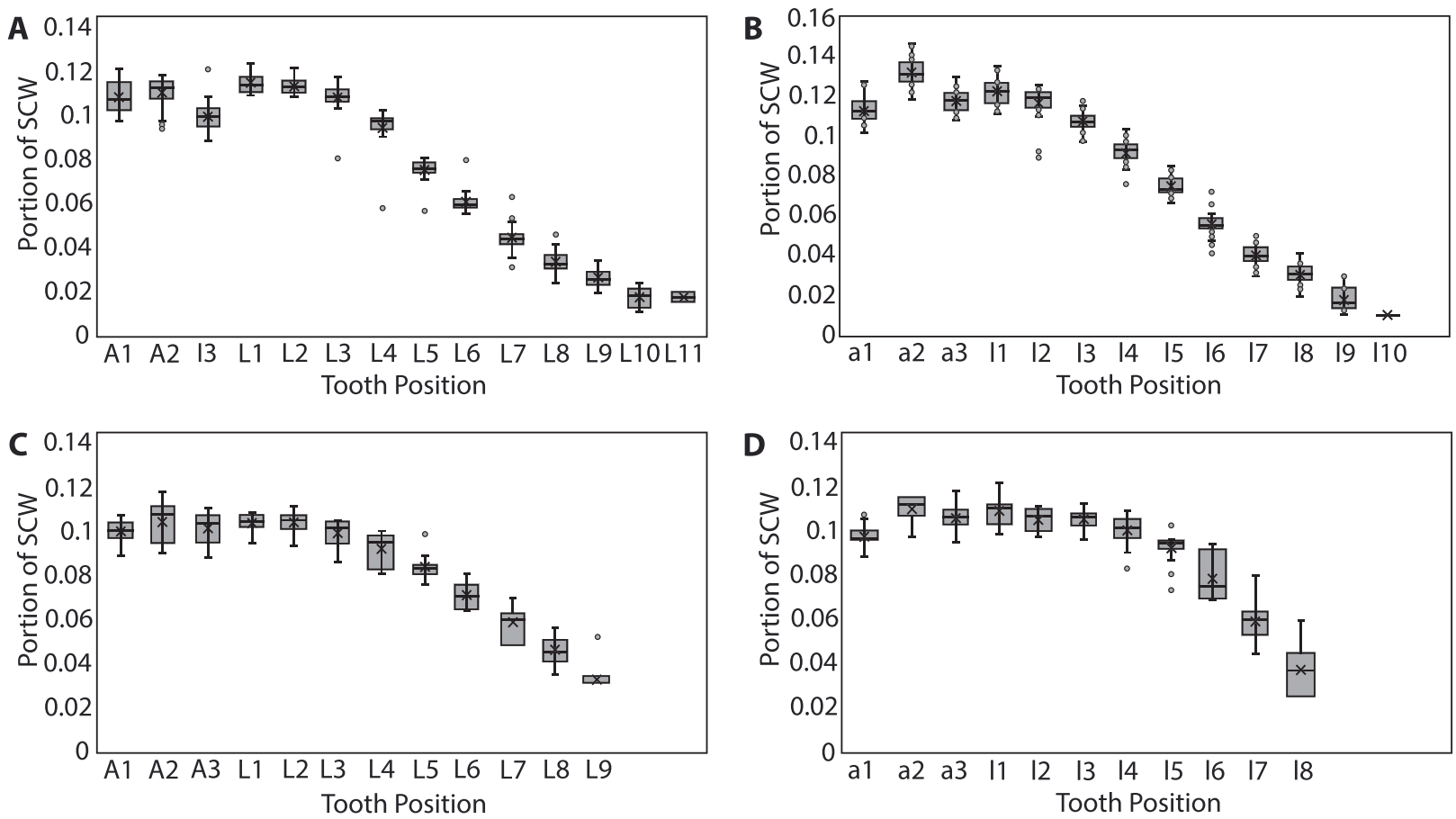

FIGURE 6. Portion of summed crown width (SCW) for each tooth position. (A-B) Proportions from 10 modern Carcharodon carcharias dentitions. (C-D) Proportions from all eight fossil Otodus associated dentitions, after applying correction factors. (A, C) upper and (B, D) lower. Correction factors were derived from these proportions (see Appendix 5). 
TABLE 3. Body length estimates from 11 fossil dentitions of Otodus and Carcharodon. Summed crown width measured $(\mathrm{SCWms})$ and corrected $(\mathrm{SCWc})$, and total body length $(\mathrm{TL}) .{ }^{*}$ denotes the best estimate. $\mathrm{UL}=$ upper left, $\mathrm{UR}=$ upper right, $\mathrm{LL}=$ lower left, and $\mathrm{LR}=$ lower right.

\begin{tabular}{|c|c|c|c|c|c|}
\hline Catalog \# & Position & $\begin{array}{c}\mathrm{SCW}_{\mathrm{ms}} \\
(\mathrm{mm})\end{array}$ & $\begin{array}{l}\mathrm{SCW}_{\mathrm{c}} \\
(\mathrm{mm})\end{array}$ & $\begin{array}{c}\text { TL Range } \\
\text { (m) }\end{array}$ & $\begin{array}{l}\text { TL Mean } \\
\text { (m) }\end{array}$ \\
\hline \multicolumn{6}{|c|}{ Otodus megalodon } \\
\hline GHC 6 & L1-L2 & 133 & $1266.7-1303.9$ & $17.4-24.2$ & *20.3 \\
\hline \multirow[t]{2}{*}{ UF-VP-311000 } & UL & 1055.5 & 1093.7 & $15.1-20.3$ & *17.3 \\
\hline & LL & 852.4 & 852.4 & $17.6-26.2$ & 20.8 \\
\hline \multirow[t]{4}{*}{ GHC 1} & UL & 951.5 & 1095.0 & $15.1-20.3$ & *17.3 \\
\hline & UR & 947.3 & 1122.4 & $15.5-20.8$ & 17.7 \\
\hline & LL & 689.0 & 811.5 & $16.8-24.9$ & 19.8 \\
\hline & LR & 550.4 & 781.8 & $16.2-24.0$ & 19.1 \\
\hline \multirow[t]{4}{*}{$\mathrm{CH}-31-46 \mathrm{P}$} & UL & 783.5 & 783.5 & $10.8-14.5$ & *12.4 \\
\hline & UR & 739.5 & 790.9 & $10.9-14.7$ & 12.5 \\
\hline & LL & 612.2 & 612.2 & $12.7-18.8$ & 15.0 \\
\hline & LR & 579.2 & 611.6 & $12.6-18.8$ & 14.9 \\
\hline \multirow[t]{4}{*}{ UF-VP-460000 } & UL & 519.6 & 681.9 & $9.4-12.6$ & 10.8 \\
\hline & UR & 533.5 & 685.7 & $9.4-12.7$ & *10.9 \\
\hline & LL & 400.7 & 540.8 & $11.2-16.6$ & 13.2 \\
\hline & LR & 404.8 & 546.3 & $11.3-16.8$ & 13.3 \\
\hline \multicolumn{6}{|c|}{ Otodus chubutensis } \\
\hline \multirow[t]{3}{*}{ USNM 299832} & UL & 215.4 & 679.5 & $9.4-12.6$ & 10.7 \\
\hline & UR & 576.3 & 696.9 & $9.6-12.9$ & *11.0 \\
\hline & LR & 400.4 & 530.3 & $11.0-16.3$ & 13.0 \\
\hline \multirow[t]{4}{*}{ GHC 3} & UL & 60.1 & 707.1 & $9.7-13.1$ & 11.2 \\
\hline & UR & 668.6 & 690.7 & $9.5-12.8$ & *10.9 \\
\hline & LL & 379.2 & 497.0 & $10.3-15.3$ & 12.1 \\
\hline & LR & 542.7 & 542.7 & $11.2-16.7$ & 13.3 \\
\hline \multirow[t]{4}{*}{ USNM 411881} & UL & 491.5 & 569.5 & $7.8-10.6$ & $* 9.0$ \\
\hline & UR & 482.7 & 546.7 & $7.5-10.1$ & 8.6 \\
\hline & LL & 389.3 & 453.2 & $9.4-13.9$ & 11.1 \\
\hline & LR & 300.4 & 429.1 & $8.9-13.2$ & 10.5 \\
\hline
\end{tabular}

there are four variables, of which three can be measured $(a, b$, and $c)$ and the fourth solved for $(x)$ :

$$
\frac{a}{b}=\frac{c}{x} \Rightarrow \frac{S C W_{m}}{T L_{m}}=\frac{S C W_{f}}{T L_{f}}
$$

Body length estimates were calculated using three extant lamniform species as analogs: $C$. carcharias $(\mathrm{n}=17)$, Isurus oxyrinchus $(\mathrm{n}=1)$, and Isurus paucus $(\mathrm{n}=1)$. Body length estimates derived from different modern analogs highlights 
TABLE 3 (continued).

\begin{tabular}{|c|c|c|c|c|c|}
\hline Catalog \# & Position & $\begin{array}{c}\mathrm{SCW}_{\mathrm{ms}} \\
(\mathrm{mm})\end{array}$ & $\begin{array}{l}\mathrm{SCW}_{\mathrm{C}} \\
(\mathrm{mm})\end{array}$ & $\begin{array}{l}\text { TL Range } \\
\text { (m) }\end{array}$ & $\begin{array}{l}\text { TL Mean } \\
\text { (m) }\end{array}$ \\
\hline \multirow[t]{4}{*}{ UF-VP-312864 } & UL & 357.9 & 376.3 & $5.2-7.0$ & *5.9 \\
\hline & UR & 269.1 & 379.5 & $5.2-7.0$ & 6.0 \\
\hline & LL & 299.0 & 336.0 & $6.9-10.3$ & 8.2 \\
\hline & LR & 174.3 & 305.3 & $6.3-9.4$ & 7.5 \\
\hline \multicolumn{6}{|c|}{ Carcharodon hastalis } \\
\hline \multirow[t]{4}{*}{ GHC 5} & UL & 301.2 & 336.5 & $4.6-6.2$ & 5.3 \\
\hline & UR & 322.9 & 331.5 & $4.6-6.1$ & *5.2 \\
\hline & LL & 232.1 & 253.9 & $5.2-7.8$ & 6.2 \\
\hline & LR & 219.2 & 223.0 & $4.5-6.9$ & 5.4 \\
\hline \multicolumn{6}{|c|}{ Carcharodon hubbelli } \\
\hline \multirow[t]{4}{*}{ UF-VP-226255 } & UL & 291.4 & 299.2 & $4.1-5.5$ & 4.7 \\
\hline & UR & 313.0 & 313.0 & $4.3-5.8$ & *4.9 \\
\hline & LL & 225.4 & 229.3 & $4.7-7.0$ & 5.6 \\
\hline & LR & 189.2 & 220.3 & $4.5-6.8$ & 5.4 \\
\hline \multicolumn{6}{|c|}{ Carcharodon carcharias } \\
\hline \multirow[t]{4}{*}{ GHC 4} & UL & 191.6 & 256.1 & $3.5-4.8$ & 4.0 \\
\hline & UR & 249.7 & 256.4 & $3.5-4.8$ & *4.0 \\
\hline & LL & 88.4 & 187.3 & $3.9-5.8$ & 4.6 \\
\hline & LR & 178.5 & 195.3 & $4.0-6.0$ & 4.8 \\
\hline
\end{tabular}

interspecific and intraspecific variation in the relationship between SCW and TL. The rule of three method was applied for each region of the fossil dentitions preserved (upper left, upper right, lower left, and/or lower right) with all 19 modern analogs. Among the 19 modern analogs, eight only had half of the dentition preserved (left or right). Thus, for a single fossil dentition with all four quadrants preserved, there were a total of 120 different body length estimates. The range and mean body length estimates from each region of the jaw were calculated (Eq. 3). This equation is similar to a linear regression, where the calculated mean approximates the linear trendline and the range captures the extent of variance around the mean. The benefit of calculating TL with this equation is the ability to quickly compare estimates derived from specific, individual modern analogs and better explain the source of variance around the mean.

$$
T L=\operatorname{mean}\left(x_{1}=\frac{b_{1} * c_{1}}{a_{1}}, x_{2}=\frac{b_{2} * c_{2}}{a_{2}}, \ldots, x_{n}=\frac{b_{n} * c_{n}}{a_{n}}\right) \quad \text { Eq. } 3
$$

\section{Extrapolation for Isolated Teeth}

The correction factors that were calculated using the modern dentitions of Carcharodon carcharias and the most complete fossil associated dentitions of Otodus spp. were used to estimate body size from isolated teeth. To extrapolate the SCW method in this manner, one must first determine which associated dentition to use as an analog to approximate the appropriate tooth position. For example, if you wish to estimate the size from an isolated $O$. megalodon tooth, then you could use either the adult individual (UF-VP-311000) or the juvenile individual $(\mathrm{CH}-31-46 \mathrm{P})$ as your analog to do so. If you are uncertain which is the best analog, then body length should be calculated using both models and an average estimate should be reported. If a tooth cannot be identified to a specific tooth position, then a range of potential positions and corresponding body lengths should be reported.

This extrapolated version of the SCW method offers the opportunity to re-assess body size esti- 
mates in previous paleoecological studies (i.e., Pimiento et al., 2010; Pimiento and Balk, 2015; Herraiz et al., 2020) and compare them with estimates derived from the Shimada (2002a, 2019) isolated $\mathrm{CH}$ method. Body length estimates were re-calculated using a subset of the Pimiento and Balk (2015) sample. The SCW method was applied by using proportions from $\mathrm{CH}-31-46 \mathrm{P}$ and UF-VP311000 separately. The average of these two estimates was compared to those reported by Pimiento and Balk (2015) to determine if there was a predictable variation in body length estimates based on the tooth position assigned.

The SCW method was also extrapolated to estimate the maximum body size of Otodus megalodon, using the isolated tooth with the widest known crown width ( $\mathrm{GHC} 6$; $\mathrm{CW}=133 \mathrm{~mm}$ ). The tooth position was assigned based on a comparison of the $\mathrm{CH}: \mathrm{CW}$ ratios in the largest associated dentition of $O$. megalodon, UF-VP-311000. The corrected SCW was calculated based on the CW proportions in UF-VP-311000.

\section{RESULTS}

Segmenting the dentitions into four regions (upper left, upper right, lower left, and lower right) allowed for the inclusion of partial associated dentitions, comparison of estimates derived from the lower versus upper dentitions, and comparison of estimates derived from the left versus right sides of the dentitions. However, this also required determination as to which of the four regions provided the most reliable body length estimate. In all taxa, bilateral symmetry is generally observed; however, this symmetry is often imperfect. Body length estimates derived from the left and right sides of a single individual varied from 0 to $0.4 \mathrm{~m}$ (Table 3 ). In terms of selecting left versus right, the more complete side of the fossil dentitions is considered the more reliable estimate.

For all individuals, the mean body length estimates derived from the lower dentition were greater than estimates derived from the upper dentition (Table 3 and Figure 7). For the upper dentition, estimates using Isurus as the modern analog were greater than estimates derived from Carcharodon. For the lower dentition, estimates using Isurus as the modern analog were within the range of estimates derived from Carcharodon. These differences between the upper and lower dentitions and different modern analogs can be explained by varying tooth morphologies attributed to different functional roles and feeding ecologies (see Discussion below). Thus, the mean TL from the most complete upper half of the dentition, with C. carcharias as the modern analog, is considered the most reliable estimate (Table 3).

For the four individuals of 0 . megalodon, mean body lengths estimates were 10.9, 12.4, 17.3 , and $17.3 \mathrm{~m}$, respectively. Using the same modern comparative dataset, the body length estimates for the four individuals of $O$. chubutensis were 5.9, 9.0, 10.9, and $11.0 \mathrm{~m}$, respectively. Only a single individual of $C$. carcharias, $C$. hubbelli, and C. hastalis were used in this study, which resulted in body length estimates of $4.0,4.9$, and $5.1 \mathrm{~m}$, respectively.

The single individual of Carcharodon hubbelli, UF-VP-226255, was the only fossil specimen found as an articulated skeleton, comprised of 222 teeth and 45 vertebral centra. Ehret et al. (2009) applied body length equations based on regressions of vertebral diameter and vertebral radius, proposed by Cailliet et al. (1985), Gottfried et al. (1996), Wintner and Cliff (1999), and Natanson (2001). These body length estimates based on vertebral measurements ranged from 4.7 to $5.2 \mathrm{~m}$, with a mean estimate of $4.9 \mathrm{~m}$. Ehret et al. (2009) also applied the Shimada (2002a) method, resulting in a range of estimates from 3.0 to $7.0 \mathrm{~m}$, with a mean estimate of $5.1 \mathrm{~m}$. The SCW method resulted in a range of estimates from 4.1 to $5.8 \mathrm{~m}$, with a mean estimate of $4.9 \mathrm{~m}$.

The Shimada (2002a, 2019) methods were applied to the 11 fossil dentitions for comparison (Figure 7 and Table 4). Body length estimates based on the Shimada (2002a) method resulted in a wider range of estimates than the SCW method described herein. For Otodus individuals, body length estimates based on the Shimada (2019) method were lower than the SCW method applied herein. For Carcharodon individuals, body length estimates based on the Shimada (2019) method were within $0.5 \mathrm{~m}$ of estimates based on SCW.

Extrapolating the SCW method for the largest known isolated tooth of 0 . megalodon (GHC 6) resulted in a corrected summed crown width ranging from 1266.7 to $1303.9 \mathrm{~mm}$. Based on a SCW of $1266.7 \mathrm{~mm}$, the SCW method results in a TL of 17.4 to $23.5 \mathrm{~m}$, with a mean estimate of $20.0 \mathrm{~m}$. Based on a SCW of $1303.9 \mathrm{~mm}$, the SCW method results in a TL of 18.0 to $24.2 \mathrm{~m}$, with a mean estimate of $20.6 \mathrm{~m}$. 

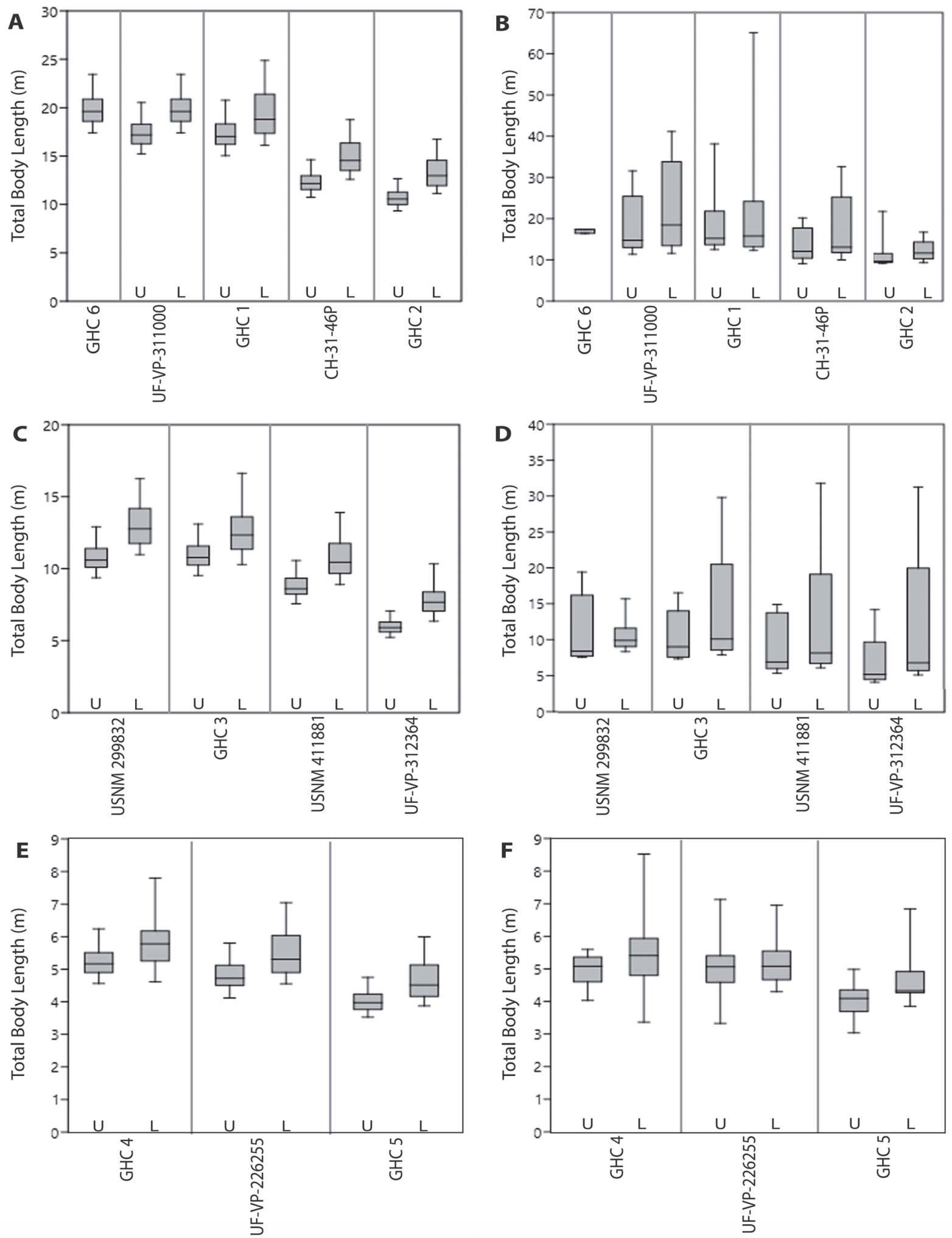

FIGURE 7. Comparison of body length estimates based on SCW direct proportions and Shimada (2002a) $\mathrm{CH}$ linear regression. (A-B) Otodus megalodon; (C-D) Otodus chubutensis; and (E-F) Carcharodon spp. (A, C, E) SCW direct proportions. (B, D, F) Shimada (2002a) $\mathrm{CH}$ linear regression. $U=$ upper and $\mathrm{L}=$ lower. 
Perez, Leder, \& Badaut: Estimating LAMNiform Body Size

TABLE 4. Comparison of different methods for estimating body length: Shimada (2002a), Shimada (2019), and this study. All estimates are in meters. ${ }^{*}$ denotes the best estimate. UL = upper left, UR = upper right, LL = lower left, and LR $=$ lower right.

\begin{tabular}{|c|c|c|c|c|c|c|c|}
\hline Catalog \# & $\begin{array}{c}\text { Tooth } \\
\text { Position }\end{array}$ & $\begin{array}{l}\text { Shimada } \\
(2002 a)\end{array}$ & $\begin{array}{c}\text { Shimada } \\
(2019)\end{array}$ & $\begin{array}{c}\text { SCW } \\
\text { (Range) }\end{array}$ & $\begin{array}{c}\text { SCW } \\
\text { (Mean) }\end{array}$ & $\begin{array}{c}\text { SCW } \\
\text { (Linear Fn) }\end{array}$ & $\begin{array}{c}\text { SCW } \\
\text { (Power Fn) }\end{array}$ \\
\hline \multicolumn{8}{|c|}{ Otodus megalodon } \\
\hline GHC 6 & L1-L2 & $16.4-17.4$ & - & $17.4-24.2$ & *20.3 & *20.1 & 21.6 \\
\hline \multirow[t]{2}{*}{ UF-VP-311000 } & UL & $11.4-31.6$ & 12.0 & $15.1-20.3$ & *17.3 & *17.3 & 18.5 \\
\hline & LL & $11.6-41.1$ & 10.3 & $17.6-26.2$ & 20.8 & 21.6 & 24.8 \\
\hline \multirow[t]{4}{*}{ GHC 1} & UL & $12.5-38.1$ & 12.3 & $15.1-20.3$ & *17.3 & *17.4 & 18.5 \\
\hline & UR & $13.1-30.0$ & 12.8 & $15.5-20.8$ & 17.7 & 17.8 & 19.0 \\
\hline & LL & $13.1-65.1$ & 10.7 & $16.8-24.9$ & 19.8 & 20.6 & 23.5 \\
\hline & LR & $12.3-29.1$ & 10.5 & $16.2-24.0$ & 19.1 & 19.8 & 22.5 \\
\hline \multirow[t]{4}{*}{$\mathrm{CH}-31-46 \mathrm{P}$} & UL & $9.3-19.8$ & 9.3 & $10.8-14.5$ & *12.4 & *12.4 & 13.0 \\
\hline & UR & $9.1-20.2$ & 9.3 & $10.9-14.7$ & 12.5 & 12.5 & 13.1 \\
\hline & LL & $9.8-31.8$ & 8.7 & $12.7-18.8$ & 15.5 & 15.5 & 17.2 \\
\hline & LR & $10.0-32.6$ & 8.7 & $12.6-18.8$ & 15.5 & 15.5 & 17.1 \\
\hline \multirow[t]{4}{*}{ UF-VP-460000 } & UL & $9.3-19.4$ & 9.7 & $9.4-12.6$ & 10.8 & 10.8 & 11.2 \\
\hline & UR & $9.2-21.8$ & 9.3 & $9.4-12.7$ & *10.9 & *10.9 & 11.3 \\
\hline & LL & $9.3-16.7$ & 8.3 & $11.2-16.6$ & 13.7 & 13.7 & 14.9 \\
\hline & LR & $9.8-16.6$ & 8.6 & $11.3-16.8$ & 13.8 & 13.8 & 15.1 \\
\hline \multicolumn{8}{|c|}{ Otodus chubutensis } \\
\hline \multirow[t]{3}{*}{ USNM 299832} & UL & $7.7-10.0$ & - & $9.4-12.6$ & 10.7 & 10.8 & 11.2 \\
\hline & UR & $7.5-19.4$ & - & $9.6-12.9$ & $* 11.0$ & $* 11.0$ & 11.5 \\
\hline & LR & $8.4-15.7$ & 7.6 & $11.0-16.3$ & 13.0 & 13.4 & 14.6 \\
\hline \multirow[t]{4}{*}{ GHC 3} & UL & - & - & $9.7-13.1$ & 11.2 & 11.2 & 11.7 \\
\hline & UR & $7.3-16.5$ & 7.5 & $9.5-12.8$ & *10.9 & *10.9 & 11.3 \\
\hline & LL & $8.1-23.7$ & - & $10.3-15.3$ & 12.1 & 12.5 & 13.6 \\
\hline & LR & $7.9-29.8$ & 7.3 & $11.2-16.7$ & 13.3 & 13.7 & 15.0 \\
\hline \multirow[t]{4}{*}{ USNM 411881} & UL & $5.5-13.9$ & 5.9 & $7.8-10.6$ & *9.0 & *9.0 & 9.3 \\
\hline & UR & $5.3-14.9$ & 6.0 & $7.5-10.1$ & 8.6 & 8.6 & 8.9 \\
\hline & LL & $6.3-31.8$ & 6.1 & $9.4-13.9$ & 11.1 & 11.4 & 12.3 \\
\hline & LR & $6.1-26.5$ & 5.9 & $8.9-13.2$ & 10.5 & 10.8 & 11.6 \\
\hline \multirow[t]{4}{*}{ UF-VP-312864 } & UL & $4.1-14.2$ & 4.3 & $5.2-7.0$ & *5.9 & *5.9 & 6.0 \\
\hline & UR & $4.4-10.8$ & 4.5 & $5.2-7.0$ & 6.0 & 6.0 & 6.0 \\
\hline & LL & $5.1-31.3$ & 5.2 & $6.9-10.3$ & 8.2 & 8.4 & 8.8 \\
\hline & LR & $5.6-24.1$ & - & $6.3-9.4$ & 7.5 & 7.6 & 7.9 \\
\hline \multicolumn{8}{|c|}{ Carcharodon hastalis } \\
\hline \multirow[t]{4}{*}{ GHC 5} & UL & $4.5-5.6$ & 5.6 & $4.6-6.2$ & 5.3 & 5.3 & 5.3 \\
\hline & UR & $4.0-5.5$ & 5.5 & $4.6-6.1$ & *5.2 & *5.2 & 5.2 \\
\hline & LL & $4.6-8.5$ & 5.9 & $5.2-7.8$ & 6.2 & 6.3 & 6.4 \\
\hline & LR & $3.4-6.1$ & 5.5 & $4.5-6.9$ & 5.4 & 5.5 & 5.6 \\
\hline
\end{tabular}


TABLE 4 (continued).

\begin{tabular}{|c|c|c|c|c|c|c|c|}
\hline Catalog \# & $\begin{array}{c}\text { Tooth } \\
\text { Position }\end{array}$ & $\begin{array}{c}\text { Shimada } \\
(2002 a)\end{array}$ & $\begin{array}{c}\text { Shimada } \\
(2019)\end{array}$ & $\begin{array}{c}\text { SCW } \\
\text { (Range) }\end{array}$ & $\begin{array}{c}\text { SCW } \\
\text { (Mean) }\end{array}$ & $\begin{array}{c}\text { SCW } \\
\text { (Linear Fn) }\end{array}$ & $\begin{array}{c}\text { SCW } \\
\text { (Power Fn) }\end{array}$ \\
\hline \multicolumn{8}{|c|}{ Carcharodon hubbelli } \\
\hline \multirow[t]{4}{*}{ UF-VP-226255 } & UL & $4.4-7.1$ & 4.4 & $4.1-5.5$ & 4.7 & 4.7 & 4.7 \\
\hline & UR & $3.3-6.1$ & 4.4 & $4.3-5.8$ & *4.9 & *4.9 & 4.9 \\
\hline & LL & $4.3-7.0$ & 4.3 & $4.7-7.0$ & 5.6 & 5.7 & 5.8 \\
\hline & LR & $4.3-5.8$ & 4.3 & $4.5-6.8$ & 5.4 & 5.5 & 5.5 \\
\hline \multicolumn{8}{|c|}{ Carcharodon carcharias } \\
\hline \multirow[t]{4}{*}{ GHC 4} & UL & $3.0-4.8$ & 4.1 & $3.5-4.8$ & 4.0 & 4.0 & 4.0 \\
\hline & UR & $3.1-5.0$ & 4.3 & $3.5-4.8$ & *4.0 & *4.0 & 4.0 \\
\hline & LL & $4.0-4.6$ & 4.4 & $3.9-5.8$ & 4.6 & 4.6 & 4.6 \\
\hline & LR & $3.9-6.8$ & 4.4 & $4.0-6.0$ & 4.8 & 4.8 & 4.8 \\
\hline
\end{tabular}

\section{DISCUSSION}

\section{Accounting for Error}

There are a few different potential sources of error that could impact body length estimates using the SCW direct proportionality method. These sources can be broadly grouped into three categories: natural variation, human observer error, and mathematical assumptions. Natural variation in tooth proportions occurs within individuals, within species, and between species, which could introduce error to our body length estimates. Human error could be introduced while measuring teeth or through assumptions related to the dental count and pattern of fossil dentitions. Assumptions regarding the optimal mathematical equation introduce yet another avenue for error. Accounting for each source of error offers constraints on the potential accuracy of body length estimates proposed in this study and in previous studies.

Natural variation. Variation within individuals was accounted for by comparing estimates between the four quadrants in the dentition. Given that all individuals exhibit bilateral symmetry, there is minimal variation between the left and right sides of the dentition (i.e., $<0.5 \mathrm{~m}$ difference in TL estimates). This was accounted for by simply selecting the side of the fossil dentition that was most completely preserved as the superior estimate.

Greater variability was observed in estimates derived from the upper versus the lower dentitions, in which the lower dentition always resulted in larger TL estimates than the upper dentition (Figure 7). This consistent difference in body length estimates derived from upper and lower dentitions can be explained by two factors: function and phylogeny. There is a difference in shape and corre- sponding functionality between the lower and upper dentition (Kent, 1994; Cappetta, 2012). Lower teeth tend to be narrower and have a more robust root relative to upper teeth, which aids in penetrating and grasping prey. After the lower teeth have anchored the prey, the upper teeth then tear and cut the flesh. While both upper and lower teeth are predominantly designed for cutting, there is greater grasping functionality in lower teeth than in upper teeth. Further, this grasping functionality of the lower teeth is more apparent in representatives of the genus Carcharodon than those in the genus Otodus. Carcharodon spp. tend to have more symmetrical, vertically erect lower teeth than Otodus spp.

Within the extant comparative dataset of $C$. carcharias, SCW versus TL was plotted for the upper and lower dentitions separately (Figure 8). Both showed a strong correlation; however, the coefficient of determination between upper SCW and TL was stronger than that of the lower SCW and TL (upper: $\mathrm{R}^{2}=0.9326$ and lower: $\mathrm{R}^{2}=0.8977$ ). Thus, we concluded that the most reliable body length estimates are from the most complete upper half of the dentition. The determination that the upper dentition is more reliable than the lower dentition is in agreement with the $\mathrm{TH}$ method employed by Gottfried et al. (1996) and the $\mathrm{CH}$ method proposed by Shimada (2019). It seems plausible that the offset in TL estimates from the upper and lower jaws may be predictable and, thus, a correction factor could be calculated. Although, determining if this is the case is a task for a future research endeavor and beyond the intended scope of this manuscript.

In addition to segmenting the jaw, three modern analogs within the family Lamnidae were con- 


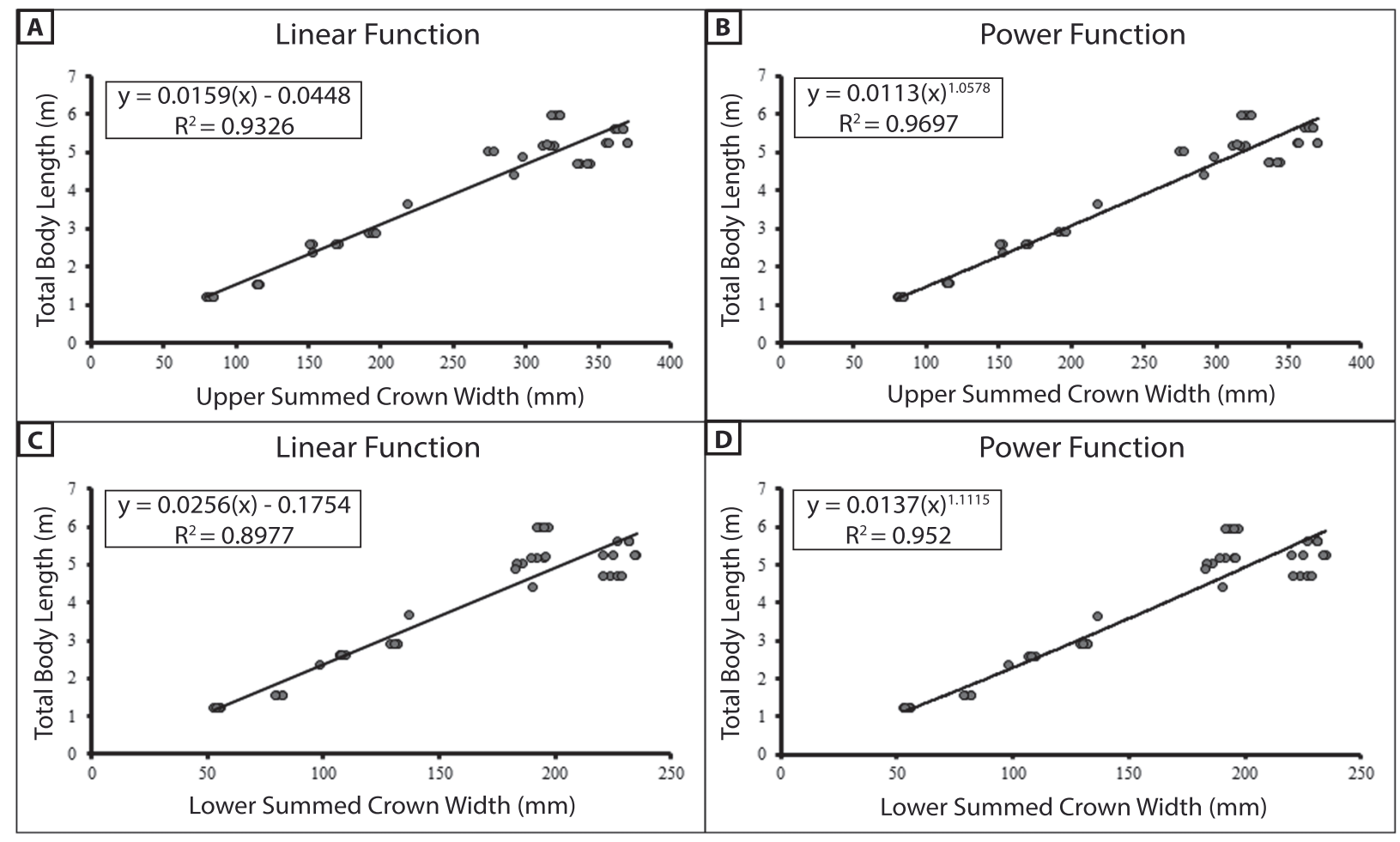

FIGURE 8. Correlation between summed crown width and total body length in 17 modern Carcharodon carcharias individuals, comparing the upper versus lower dentition. (A) linear function (upper dentition: $R^{2}=0.93$ ); $(B)$ power function (upper dentition: $R^{2}=0.97$ ); $(C)$ linear function (lower dentition: $R^{2}=0.90$ ); and (D) power function (lower dentition: $\left.R^{2}=0.95\right)$.

sidered: C. carcharias, Isurus oxyrinchus, and Isurus paucus. Body length estimates derived from the upper jaw of Isurus spp. resulted in larger body length estimates than those derived from C. carcharias. For the lower dentition, estimates using Isurus spp. as the modern analog were within the range of estimates derived from C. carcharias. While all three are macrophagous lamniform sharks, they express very different dentition types that correspond to different feeding ecologies. Isurus spp. have narrower, non-serrated teeth that serve to feed on fast swimming fishes, as opposed to the more broadly triangular, serrated teeth of $C$. carcharias that are better adapted to feeding on fleshier marine mammals (Kent, 1994; Cappetta, 2012). Similar to the functional argument that explains the differences between upper and lower estimates, the narrower teeth of Isurus spp. also result in relatively larger body length estimates. All the fossil taxa analyzed in this study have more broadly triangular teeth that are functionally more similar to C. carcharias than Isurus spp.

These differences in body length estimates between different parts of the jaw and different modern analogs highlight the importance of select- ing an ecologically similar modern analog to estimate body size. This is particularly important when attempting to estimate the size of taxa that are even more distantly related (e.g., Otodus obliquus). Cooper et al. (2020) stated that "Lamna nasus is considered the best dental analogue for both Cretalamna and Megalolamna, mako sharks (Isurus spp.) have similar dental morphology to Otodus, and $C$. carcharias has similar dentition to Otodus (Carcharocles) and Otodus (Megaselachus)." However, we feel that the typical tri-cusped morphology of teeth in O. obliquus is more akin to the teeth of the extant Lamna nasus. Future research that aims to expand this method to other taxa should take this into consideration when selecting their modern analogs.

Aside from heterodonty, ontogeny is often referenced as the greatest source of natural intraspecific variation in lamniform dentitions (Hubbell, 1996; Tomita et al., 2017). In C. carcharias, teeth tend to be narrower in juveniles and become progressively broader throughout ontogeny (Hubbell, 1996; Tomita et al., 2017). Interestingly, Tomita et al. (2017) noted that the intermediate tooth position is proportionately similar to adjacent teeth in early- 
term embryos and that the lamnoid tooth pattern is achieved in mid- to full-term embryos. Consequently, the $\mathrm{CH}$ and $\mathrm{CW}$ proportions vary throughout ontogeny. This potential ontogenetic variation is difficult to account for in the extinct megatooth lineage, particularly with the small sample of associated dentitions available. Among the four associated dentitions of Otodus megalodon, they can be grouped into two size classes: juvenile $(\mathrm{CH}-31-46 \mathrm{P}$ and UF-VP46000) and adult (UF-VP-311000 and $G H C$ 1). Consequently, correction factors for $O$. megalodon were separated into two categories (juvenile and adult) based on the most complete associated dentitions available.

While lamniform sharks generally conform to the lamnoid tooth pattern, there is undoubtedly intra- and inter-specific variation in the dental count and pattern. The general dental formula used in this study for Carcharodon carcharias had 48 teeth in its functional tooth series. However, the extant individuals measured in this study had a functional series ranging from 46 to 50 teeth (see Appendices 1 and 2). TL estimates for the largest associated dentition of $O$. megalodon, UF-VP-311000, using the 17 modern individuals of $C$. carcharias as analogs, ranged from 15.1 to $20.3 \mathrm{~m}$, with a mean estimate of $17.3 \mathrm{~m}$. TL estimates for the smallest associated dentition of $O$. megalodon, UF-VP460000 , using the same modern analogs, ranged from 9.4 to $12.7 \mathrm{~m}$, with a mean estimate of 10.9 $\mathrm{m}$. The range of estimates largely reflects the natural intraspecific variation exhibited in the modern Carcharodon carcharias used as analogs. Thus, there is an unavoidable range of error of approximately \pm 1 to $3 \mathrm{~m}$ that is accounted for simply by taking the mean value. This range of error is positively correlated with $T L$, meaning that there will always be a greater range of estimates for larger individuals.

Human observer error. The natural variability in a species dental count is difficult to account for in disarticulated, associated dentitions of extinct taxa and is, consequently, a potential source of human error. The dental count for all Otodus dentitions was based on the most complete known associated dentition ( $\mathrm{CH}-31-46 \mathrm{P})$, under the assumption that the functional series in the left half of the dentition was completely present (Figure 1B). Thus, it was assumed that a complete functional series in Otodus chubutensis and Otodus megalodon consisted of 46 teeth (24 upper and 22 lower), which meant that every associated dentition of Otodus was missing at least one posterior tooth.
It is easy to imagine how posterior teeth could be missing from these fossil dentitions. As the smallest teeth in the dentition, they are the most susceptible to being transported away through taphonomic processes and would be the easiest to simply not see while collecting the other teeth. However, there is also the possibility that some of these individuals had a dental count slightly different from that of $\mathrm{CH}-31-46 \mathrm{P}$, which would change the corrected SCW and resultant TL estimates. For example, in the largest associated dentition of $O$. megalodon, UF-VP-311000, the corrected SCW was calculated under the assumption that tooth position L9 was not found but would have been present (Figure 3A). If tooth position L9 was not missing and the teeth recovered represent the complete upper half of the dentition, the SCW would be $1055.5 \mathrm{~mm}$ and the TL estimate would be $16.7 \mathrm{~m}$ (0.6 m smaller than the current estimate). Likewise, we cannot be certain that this dentition did not have a dental count greater than that of $\mathrm{CH}$ 31-46P.

Every method that attempts to estimate body size from teeth requires one to identify tooth positions, whether working with isolated teeth or associated dentitions. When applying the Shimada (2002a) method to samples of isolated teeth, researchers often account for this by identifying teeth to a range of potential tooth positions and reporting the mean estimate. For example, Pimiento et al. (2010) identified an isolated tooth of O. megalodon (UF 246002) as belonging to tooth position L7-L9, with a $\mathrm{CH}=24.5 \mathrm{~mm}$. Applying the Shimada (2002a) method results in a range of TL estimates from 16.5 to $34.2 \mathrm{~m}$, with an average estimate of $25.2 \mathrm{~m}$. However, Pimiento et al. (2010) reported a TL of $11.5 \mathrm{~m}$ for this specimen. Under further inspection, Pimiento et al. (2010; figure S8) incorrectly reported that the TL equation for tooth position L9 from Shimada (2002a) as TL $=-10.765$ $+17.616(\mathrm{CH})$. This is actually the equation for tooth position i1 in Shimada (2002a; table 1). The correct equation for tooth position L9 in Shimada (2002a) was $T L=-62.050+142.142(\mathrm{CH})$. This obviously has a drastic effect on the body length estimate and potentially major implications for the conclusion that the Gatun Formation represented a paleonursery for $\mathrm{O}$. megalodon. Further, even with the correct equations from the Shimada (2002a) study, the range of error on the body length estimate is approximately $\pm 9 \mathrm{~m}$ for this specimen, which is much larger than any of the potential sources of error discussed so far. 
To develop the SCW method, we had to infer which tooth positions were present in the disarticulated, associated dentitions. Generally speaking, it should be relatively easy to distinguish anterior vs lateral teeth and upper vs lower teeth, based on common trends observed in the typical lamnoid tooth pattern, but it is extremely difficult to identify a single tooth to an exact tooth position without context. However, when you have multiple teeth preserved together, there is context for making that determination. With a collection of associated teeth, one can assume that the taller, more symmetrical teeth will be more anteriorly positioned and the smaller, more asymmetrical teeth will be more posteriorly positioned. Even if multiple teeth were misplaced, as long as they are identified to the correct quadrant, their $\mathrm{CW}$ will still be included in the SCW. However, this could result in inaccurate correction factors used to estimate $\mathrm{CW}$ of missing tooth positions. At present, we consider these reconstructions as a hypothetical model and accept this as a source of error that cannot yet be fully accounted for.

Yet another potential source of human observer error is introduced while measuring specimens. Linear measurements $(\mathrm{CH}$ and $\mathrm{CW})$ were recorded for teeth from 19 modern dentitions, 11 fossil associated dentitions, and one isolated fossil tooth. Despite these measurements being clearly defined, there will always be some degree of inconsistency between individuals. This source of error is often disregarded, yet it is present. For example, Shimada (2019) noted that Applegate and Espinosa-Arrubarrena (1996) incorrectly reported the $\mathrm{TH}$ for the largest known specimen of $\mathrm{O}$. megalodon as $168 \mathrm{~mm}$ and stated that the correct $\mathrm{TH}$ is $162 \mathrm{~mm}$. This changes the maximum TL estimate reported by Gottfried et al. (1996) from 15.9 to 15.3 $\mathrm{m}$. Therefore, using the TH linear regression, measurement error may account for more than $0.5 \mathrm{~m}$ difference in TL.

To account for this potential source of error, authors VJP and RML independently measured $\mathrm{CH}$ and $\mathrm{CW}$ in nine of the 19 modern analogs. Body lengths were calculated using measurements from both subsamples separately. TL estimates using the SCW method varied by less than $0.2 \mathrm{~m}$ for all individuals. Admittedly, this measurement error likely also exists in the total body lengths reported from the extant comparative individuals; however, we cannot account for this variability, as the measurements were not taken by the authors of this study.
Mathematical equations. Methods for estimating body length based on $\mathrm{TH}, \mathrm{CH}$, and SCW all follow a similar logic that teeth grow proportionately with total body length. In contrast with the results of Reolid and Molina (2015), based on the sample of modern C. carcharias from this study, for the A2 tooth position, there is comparable correlation for $\mathrm{CH}$ and $\mathrm{TL}(\mathrm{r}=0.99)$ versus $\mathrm{CW}$ and TL $(\mathrm{r}=0.97)$. Likewise, the correlation between upper SCW and TL $(r=0.97)$ is comparable (Figure $8 \mathrm{~A})$.

Shimada (2019) determined that a power function has a greater coefficient of determination $\left(R^{2}\right)$ than a linear function when analyzing the relationship between $\mathrm{CH}$ and TL. The same is true when analyzing the relationship between SCW and TL (Figure 8). This can likely be attributed to the greater variability in tooth proportions throughout ontogeny (Hubbell, 1996; Tomita et al., 2017). However, $R^{2}$ values may not be appropriate for determining which model is superior (Cornell and Berger, 1987). $R^{2}$ values are calculated differently for linear and nonlinear functions, so they are not necessarily directly comparable. Further, $\mathrm{R}^{2}$ values are influenced by factors such as sample size and sample distribution. By segmenting the dentition into multiple regions to analyze variation within individuals, we effectively increased our sample size, which has an inverse effect on $R^{2}$ values. Thus, the higher $R^{2}$ produced by the Shimada (2019) power functions do not necessarily indicate that the model is better than SCW power function in this study.

To illustrate the variability associated with different mathematical assumptions, we estimated TL using the SCW direct proportions equation, SCW linear regression equation, and the SCW power regression equation (Table 4). As is to be expected, the SCW direct proportions and linear regression result in nearly identical TL estimates. Among the Otodus spp., in the upper dentition, TL estimates vary by at most $0.1 \mathrm{~m}$; however, for the lower dentition, TL estimates vary by up to $0.8 \mathrm{~m}$. This further supports that there is greater variance in the lower dentition. For the Otodus spp., the SCW power function always results in a larger TL estimate than the SCW direct proportions or linear regression methods. Again, as one would expect, the difference in TL estimates increases with larger individuals; however, all estimates still fall within the range of estimates produced by the SCW direct proportions method. Among the Carcharodon spp., there is less than $0.1 \mathrm{~m}$ difference in estimates derived from the SCW direct proportions, linear regression, and power regression methods for both 

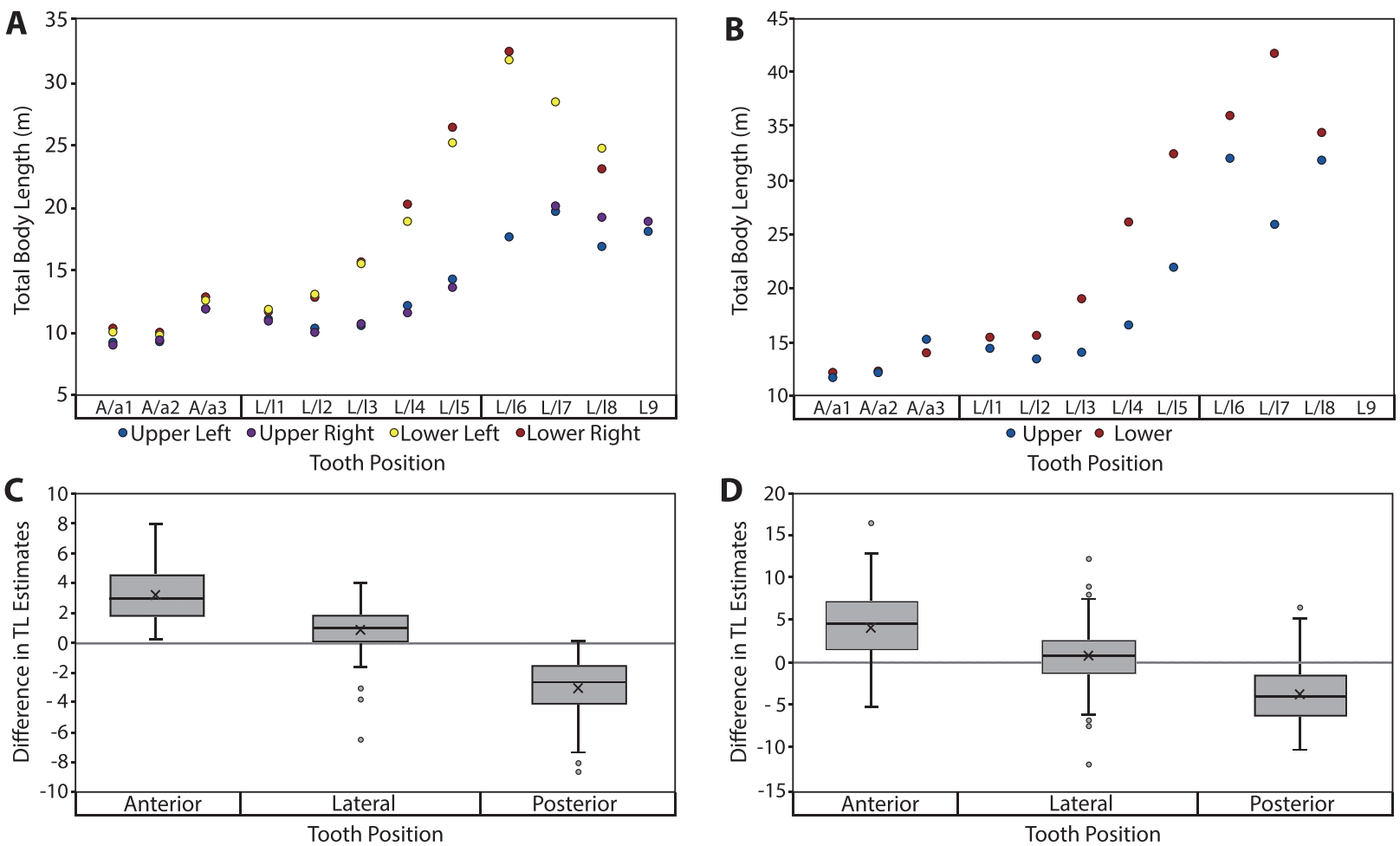

FIGURE 9. Variation in body length estimates by tooth position. (A-B) Body length estimates from each tooth position in the Otodus megalodon dentition, using the Shimada (2002a) method. (A) CH-31-46P. (B) UF-VP-311000. (C-D) Comparison of body length estimates based on the SCW vs. Shimada (2002a) CH method, using the sample of upper teeth reported in Pimiento and Balk (2015). (C) SCW calculated using tooth proportions in CH-31-46P. (D) SCW calculated using tooth proportions in UF-VP-311000. Positive values indicate that the SCW method results in larger TL estimates than the $\mathrm{CH}$ method. Negative values indicate that the SCW method results in smaller TL estimates than the $\mathrm{CH}$ method. Teeth are subdivided based on the tooth positions assigned by Pimiento and Balk (2015); however, there is some overlap between categories given that some teeth were identified as antero-lateral (e.g., A1-L1) or latero-posterior (e.g., L3-L7).

the upper and lower dentition. As such, we suggest that either the SCW direct proportions or SCW linear regression should be used to estimate $T L$ of Otodus spp., whereas the SCW direct proportions, linear regression, or power function can be used to estimate TL of Carcharodon spp.

\section{Paleoecological Implications}

Body size estimates based on $\mathrm{CH}$ of isolated Otodus megalodon teeth have been utilized to identify paleo-nurseries (Pimiento et al., 2010; Herraiz et al., 2020) and as evidence for geographically discrete communities (Pimiento and Balk, 2015). These studies all employed the $\mathrm{CH}$ linear regressions developed by Shimada (2002a) to estimate body size, which result in widely variable estimates when applied to Otodus spp. (Figure 7 and Table 4). While applying the Shimada (2002a) linear equations to the associated dentitions in this study, it became apparent that the variation in TL estimates followed a predictable trend according to tooth position, in which body length estimates generally increased from anterior to posterior tooth positions (Figure 9A-B). Further, estimates from the upper and lower dentition differed the greatest in lateral tooth positions. This variability in estimates derived from different parts of the dentition has implications for the potential of sampling bias affecting interpretations of body size trends in $O$. megalodon.

In the Pimiento and Balk (2015) study, the total sample consisted of 544 O. megalodon teeth. Of which, $355(65.2 \%)$ were identified as upper teeth and 189 (34.8\%) were identified as lower teeth. Using a subsample of the 355 upper teeth, body lengths were re-estimated by extrapolating the SCW method. In general, the SCW method resulted in larger TL estimates for anterior tooth positions and smaller estimates for posterior positions than the $\mathrm{CH}$ method (Figure 9C-D). This implies that the SCW method averages out the variation associated with estimates from different 
tooth positions and explains why the Shimada (2019) method always results in lower estimates than the SCW method.

As for the Pimiento et al. (2010) study, we pointed out that the TL equation for tooth position L9 was incorrectly transcribed from the Shimada (2002a) manuscript. Among the sample of 280. megalodon teeth from the Gatun Formation, 20 were assigned to upper tooth positions. Three of these teeth were identified as potentially belonging to tooth position L9. After re-calculating TL with the correct equation from Shimada (2002a), the estimates for these three specimens are 16.9, 17.1, and $25.2 \mathrm{~m}$ (Figure 10A). If we instead re-calculate TL using the SCW method, with a subsample of the 20 upper teeth, the range of estimates is much lower (Figure 10B). Using the SCW method, the same three specimens identified as possibly belonging to tooth position L9 result in TL estimates of $13.7,13.8$, and $11.5 \mathrm{~m}$, respectively.

As such, the SCW method would actually provide better support for the hypothesis that the Gatun Formation represented a paleo-nursery for $O$. megalodon than the $\mathrm{CH}$ method. However, there are two main caveats to this conclusion. First, the life stages derived from Gottfried et al. (1996) should be re-assessed, as it was stated that "estimated lengths and mass for megatooth fetuses and neonates ... are speculative." Shimada (2021) reported a neonate TL of $2 \mathrm{~m}$ based on growth bands in a disarticulated, associated vertebral column of Otodus megalodon (IRSNB 3121); however, this single individual is not sufficient evidence for determining the size range of all $O$. megalodon neonates. Second, if one were to use the SCW method, the conclusion regarding the presence of a paleo-nursery would be drawn from a sample of only 20 teeth. That is a fairly small sample size to support an inference about the reproductive and distribution habits of an extinct species.

\section{Maximum Body Length}

As was described in the introduction, the maximum body size of $O$. megalodon has been revised on numerous occasions. Gottfried et al. (1996) reported a conservative maximum estimate of 15.9 $\mathrm{m}$ based on a maximum $\mathrm{TH}=168 \mathrm{~mm}$ (FMNH PF 11306). However, Shimada (2019) noted that the TH for FMNH 11306 was incorrectly reported and is actually $162 \mathrm{~mm}$, which would result in a TL of $15.3 \mathrm{~m}$ using the Gottfried et al. (1996) TH linear regression. Alternatively, Shimada (2019) reported a conservative maximum estimate of $14.2 \mathrm{~m}$ based on a maximum $\mathrm{CH}=120 \mathrm{~mm}$ (NSM PV-19896).
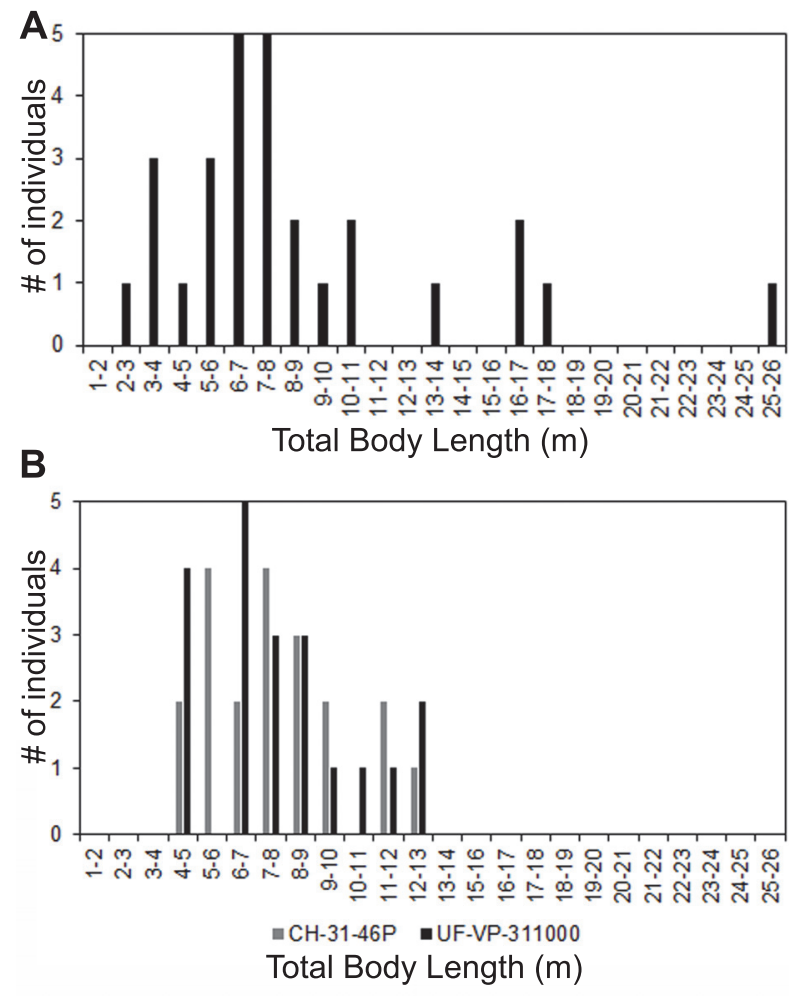

FIGURE 10. Re-calculation of Otodus megalodon body lengths from Pimiento et al. (2010). (A) Re-calculation using the correct equations from Shimada (2002a). (B) Re-calculation using the SCW direct proportions method, showing results based on $\mathrm{CH}-31-46 \mathrm{P}$ and UFVP-311000 as analogs separately.

Larger TL estimates have been reported by researchers that have attempted to employ the Shimada (2002a) CH linear regressions to isolated teeth (e.g., Pimiento et al., 2010: 16.8 m; Pimiento and Balk, 2015: $17.9 \mathrm{~m}$; Reolid and Molina, 2015: $20.3 \mathrm{~m}$ ). However, these estimates are all deemed unreliable based on errors in the data reported and the inconsistent results that are produced by the Shimada (2002a) method.

GHC 6 represents the largest tooth of Otodus megalodon known and physically accessible to the authors of this study (Figure $11 \mathrm{~A}$; TH=165 mm, $\mathrm{CH}=122 \mathrm{~mm}$, and $\mathrm{CW}=133 \mathrm{~mm}$ ). This specimen has a $\mathrm{CH}: \mathrm{CW}$ of 0.917 , which corresponds best with tooth positions L1-L2 based on the two largest associated dentitions of $O$. megalodon (UF-VP311000 and GHC 1). In UF-VP-311000, tooth position L1 accounts for $10.5 \%$ of the SCW and tooth position L2 accounts for $10.2 \%$ of the SCW (see Appendix 5). The SCW direct proportions method was extrapolated using these proportions, resulting in a corrected SCW of 1266.7 to $1303.9 \mathrm{~mm}$. 

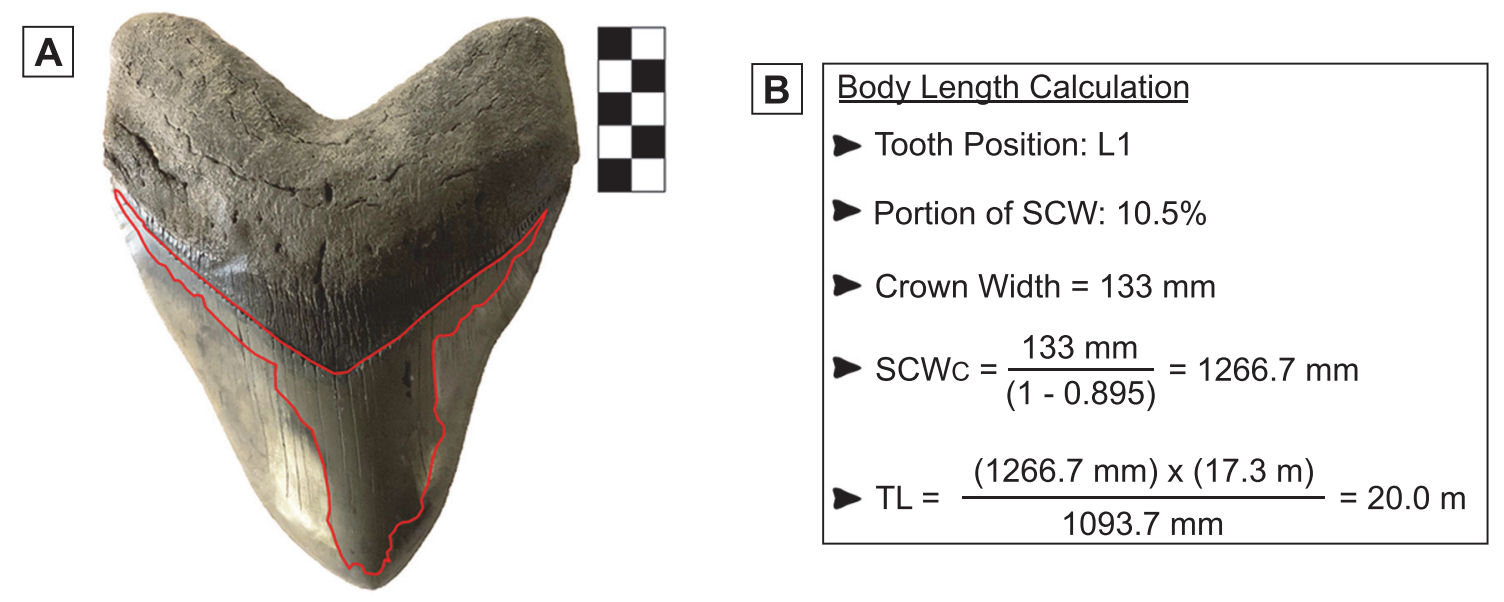

\section{C}
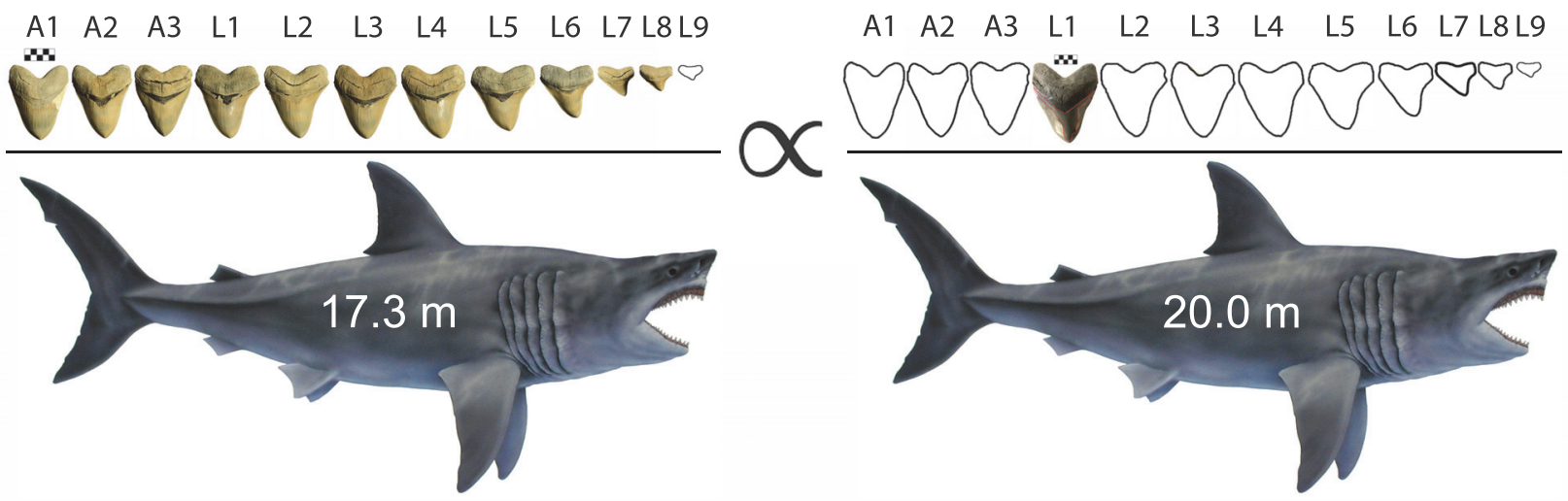

FIGURE 11. Maximum body length estimation of Otodus megalodon. (A) Widest known tooth of O. megalodon (GHC $6)$, lingual view. The tooth enamel has been repaired inside the red polygon. Scale bar equals $5 \mathrm{~cm}$. (B) Body length calculation for specimen GHC 6, using the associated dentition UF-VP-311000 as an analog and assuming the tooth represents position $\mathrm{L} 1 . \mathrm{SCW}_{\mathrm{C}}=$ summed crown width corrected and $\mathrm{TL}=$ total body length. $(\mathrm{C})$ Illustration depicting the mathematical equation used to solve for body length. Otodus megalodon artwork by Tim Scheirer, used with permission from the Calvert Marine Museum.

Based on a SCW of $1266.7 \mathrm{~mm}$, the TL estimates ranged from 17.4 to $23.5 \mathrm{~m}$, with a mean estimate of $20.0 \mathrm{~m}$. Based on a SCW of $1303.9 \mathrm{~mm}$, the TL estimates ranged from 18.0 to $24.2 \mathrm{~m}$, with a mean estimate of $20.6 \mathrm{~m}$.

One can quickly calculate the mean estimate by directly comparing the proportions in UF-VP311000 and GHC 6 (Figure 11). This follows the same principle that was used to develop the SCW method. Since we are estimating body size based on the tooth with the widest known CW, it seems reasonable to assume that this tooth also represented the widest tooth in the dentition from which it originated. In which case, the proportions of tooth position L1 from UF-VP-311000 should result in the best estimate. For this tooth position, the SCW direct proportions method results in a TL of $20.0 \mathrm{~m}$, the SCW linear regression results in a TL of 20.1 $\mathrm{m}$, and the SCW power regression results in a TL of $21.6 \mathrm{~m}$. We assume that the power regression overestimates the TL and that the SCW direct proportions and linear regression produce the more reliable estimate. As such, we predict a maximum body size for $O$. megalodon of approximately 20.0 $\mathrm{m}$.

\section{CONCLUSION}

Through an evaluation of body length estimates using fossil associated dentitions, it is evident that estimates based on crown height of isolated teeth are highly variable when applied to different tooth positions. Further, this variability follows a predictable trend, in which anterior teeth result in smaller estimates than posterior teeth. This has clear implications for previous studies that 
have employed the Shimada (2002a) $\mathrm{CH}$ method to analyze paleoecological and macroevolutionary trends based on body size of Otodus megalodon.

Herein, a novel method was developed based on summed crown width using fossil associated dentitions. By segmenting the associated dentitions into different regions, we were able to assess different sources of error that can affect body size estimation of fossil lamniform sharks. Specifically, estimates based on upper teeth are likely more accurate than estimates based on lower teeth. This is largely attributed to differences in the functional role of upper versus lower teeth. This method provides significantly greater constraint on the resultant body length estimate than the isolated $\mathrm{CH}$ method but requires assumptions about the dental pattern and count in the extinct megatooth lineage. These associated dentitions represent the most holistic direct evidence available to reconstruct the dental and cranial anatomy of the megatooth lineage but should still be treated as hypothetical models until an articulated dentition is recover.

Based on a sample of 17 modern C. carcharias dentitions, there was an approximately \pm 1 to 3 $\mathrm{m}$ range of error in TL estimates for the eight associated dentitions of Otodus spp. that can be attributed to natural intraspecific variation. This range of error increases for larger individuals. While the sample size of fossil associated dentitions is not large enough to determine the size range of the taxa analyzed in this study, we did extrapolate the SCW method for the tooth of $O$. megalodon with widest crown width (GHC 6) to provide a maximum body size estimate. Assuming this tooth represents position L1, the SCW direct proportionality method results in a maximum body length estimate of $20.0 \mathrm{~m}$ for $O$. megalodon, with a range of error of approximately $\pm 3.5 \mathrm{~m}$. Again, this range of error reflects the natural variation in the modern sample of Carcharodon carcharias used to calculate TL.

\section{ACKNOWLEDGEMENTS}

This project would not have been possible without the mentorship and support from G. Hubbell. Thank you for sharing your invaluable knowledge on lamniform anatomy and evolution and donating many of the specimens utilized in this study. Thank you to S. Godfrey and D. Bohaska for coordinating access to the Smithsonian collections. We also appreciate personal communications with M. Siversson and K. Shimada on previous studies relevant to this research. Thank you to B. MacFadden, D. Jones, E. Martin, K. Bjorndal, and K. Crippen for assistance in editing this manuscript and advising us throughout this research project. Finally, thank you to the reviewers and PE editorial team for your valuable feedback. This study is based upon work supported by the Florida Education Fund McKnight Doctoral Fellowship, the National Science Foundation Graduate Research Fellowship program (Grant No. DGE-1315138), and the National Science Foundation Advancing Informal STEM Learning program (Grant No. DRL1322725). This manuscript is University of Florida contribution to paleobiology number 879 .

\section{REFERENCES}

Agassiz, L. 1833-1844. Recherches sur les poissons fossiles. Petitpierre, Neuchatel.

Applegate, S.P. 1965. Tooth terminology and variation in sharks with special reference to the sand shark Carcharias taurus Rafinesque. Los Angeles County Museum Contributions in Science, 86:1-18.

Applegate, S.P. and Espinosa-Arrubarrena, L. 1996. The fossil history of Carcharodon and its possible ancestor, Cretolamna: a study in tooth identification, p. 19-36. In Klimley, A.P. and Ainley, D.G. (eds.), Great White Sharks: The Biology of Carcharodon carcharias. Academic Press, San Diego, CA.

Bendix-Almgreen, S.E. 1983. Carcharodon megalodon from the Upper Miocene of Denmark, with comments on elasmobranch tooth enameloid: coronoïn. Bulletin of the Geological Society of Denmark, 32(1-2):1-32.

Bourdon, J. 2005. Dentition reconstructions science or fantasy. Accessed on October 20, 2020. http://elasmo.com/genera/reconstruct/the_recon.html

Cailliet, G.M., Natanson, L.J., Welden, B.A., and Ebert, D.A. 1985. Preliminary studies on the age and growth of the white shark, Carcharodon carcharias, using vertebral bands. Memoirs of the Southern California Academy of Sciences, 9(4):49-60. 
Cappetta, H. 1987. Chondrichthyes II: Mesozoic and Cenozoic Elasmobranchii. G Fischer Verlag, Stuttgart, New York.

Cappetta, H. 2012. Chondrichthyes: Mesozoic and Cenozoic Elasmobranchii: Teeth. Handbook of Paleoichthyology, 3E. Friedrich Pfeil Verlag, München.

Casier, E. 1960. Note sur la collection des poissons paléocènes et éocènes de l'Enclave de Cabinda (Congo). Annales du Musée du Congo Belge, Sér. Minéralogie Géologie, Paléontologie, 1(2):1-48.

Castro, J.I. 2012. A summary of observations on the maximum size attained by the white shark, Carcharodon carcharias, p. 85-90. In Domeier, M.L. (ed.), Global Perspectives on the Biology and Life History of the White Shark. CRC Press, Taylor \& Francis Group, Boca Raton, FL.

Cooper, J.A., Pimiento, C., Ferrón, H.G., and Benton, M.J. 2020. Body dimensions of the extinct giant shark Otodus megalodon: a 2D reconstruction. Scientific Reports, 10(1):1-9. https://doi.org/10.1038/s41598-020-71387-y

Cornell, J.A. and Berger, R.D. 1987. Factors that influence the value of the coefficient of determination in simple linear and nonlinear regression models. Phytopathology, 77(1):6370.

Dean, B. 1909. The giant of ancient sharks. The American Museum Journal, 9(8):233-234.

Ehret, D.J., Hubbell, G., and MacFadden, B.J. 2009. Exceptional preservation of the white shark Carcharodon (Lamniformes, Lamnidae) from the early Pliocene of Peru. Journal of Vertebrate Paleontology, 29(1):1-13. https://doi.org/10.1671/039.029.0113

Ehret, D.J., MacFadden, B.J., Jones, D.S., Devries, T.J., Foster, D.A., and Salas?Gismondi, R. 2012. Origin of the white shark Carcharodon (Lamniformes: Lamnidae) based on recalibration of the Upper Neogene Pisco Formation of Peru. Palaeontology, 55(6):11391153. https://doi.org/10.1111/j.1475-4983.2012.01201.x

Glickman, L.S. 1964. Class Chondrichthyes, Subclass Elasmobranchii, (in Russian), p. 196-237. In Obruchev, D.V. (ed.), Fundamentals of Paleontology, Volume 11. Nauka SSSR, Moscow and Leningrad. [English translation 1967, p. 292-352. Israel Program for Scientific Translations, Jerusalem]

Gottfried, M.D., Compagno, L.J.V., and Bowman, S.C. 1996. Size and skeletal anatomy of the giant megatooth shark Carcharodon megalodon, p. 55-89. In Klimley, A.P. and Ainley, D.G. (eds.), Great White Sharks: The Biology of Carcharodon carcharias. Academic Press, San Diego, CA.

Grant, C.A., MacFadden, B.J., Antonenko, P., and Perez, V.J. 2017. 3-D Fossils for K-12 education: a case example using the giant extinct shark, Carcharocles megalodon. The Paleontological Society Papers, 22:197-209. https://doi.org/10.1017/scs.2017.15

Herraiz, J.L., Ribé, J., Botella, H., Martínez-Pérez, C., and Ferrón, H.G. 2020. Use of nursery areas by the extinct megatooth shark Otodus megalodon (Chondrichthyes: Lamniformes). Biology Letters, 16(11):p.20200746. https://doi.org/10.1098/rsbl.2020.0746

Hubbell, G. 1996. Using tooth structure to determine the evolutionary history of the white shark, p. 9-18. In Klimley, A.P. and Ainley, D.G. (eds.), Great White Sharks: The Biology of Carcharodon carcharias. Academic Press, San Diego, CA.

Jordan, D.S. and Hannibal, H. 1923. Fossil sharks and rays of the Pacific slope of North America. Bulletin of the Southern California Academy of Sciences, 23:27-63.

Kent, B.W. 1994. Fossil Sharks of the Chesapeake Bay Region. Egan Rees and Boyer, Inc., Columbia, MD.

Kent, B.W. 2018. The cartilaginous fishes (chimaeras, sharks, and rays) of Calvert Cliffs, Maryland, USA, p. 45-157. In Godfrey, S.J. (ed.), The Geology and Vertebrate Paleontology of Calvert Cliffs, Maryland, USA. Smithsonian Institution Scholarly Press.

Lowry, D., de Castro, A.L.F., Mara, K., Whitenack, L.B., Delius, B., Burgess, G.H., and Motta, P. 2009. Determining shark size from forensic analysis of bite damage. Marine Biology, 156(12):2483-2492. https://doi.org/10.1007/s00227-009-1273-3

McClain, C.R., Balk, M.A., Benfield, M.C., Branch, T.A., Chen, C., Cosgrove, J., Dove, A.D., Gaskins, L.C., Helm, R.R., Hochberg, F.G., and Lee, F.B., 2015. Sizing ocean giants: patterns of intraspecific size variation in marine megafauna. PeerJ, 3:p.e715. https://doi.org/10.7717/ peerj.715

Natanson, L.J. 2001. Preliminary investigations into the age and growth of the shortfin mako, Isurus oxyrinchus, white shark, Carcharodon carcharias, and thresher shark, Alopias vulpinus, in the Western North Atlantic Ocean. International Commission for the Conservation of Atlantic Tunas Working Document, Standing Committee on Research and 
Statistics, 1:1-66.

Newbrey, M.G., Siversson, M., Cook, T.D., Fotheringham, A.M., and Sanchez, R.L. 2015. Vertebral morphology, dentition, age, growth, and ecology of the large lamniform shark Cardabiodon ricki. Acta Palaeontologica Polonica, 60(4):877-897. https://doi.org/10.4202/app.2012.0047

Nyberg, K.G., Ciampaglio, C.N., and Wray, G.A. 2006. Tracing the ancestry of the great white shark. Journal of Vertebrate Paleontology, 26:806-814. https://www.jstor.org/stable/4524633

Perez, V.J., Godfrey, S.J., Kent, B.W., Weems, R.E., and Nance, J.R. 2019. The transition between Carcharocles chubutensis and Carcharocles megalodon (Otodontidae, Chondrichthyes): lateral cusplet loss through time. Journal of Vertebrate Paleontology, 38(6):p.e1546732. https://doi.org/10.1080/02724634.2018.1546732

Pimiento, C., Ehret, D.J., MacFadden, B.J., and Hubbell, G. 2010. Ancient nursery area for the extinct giant shark Megalodon from the Miocene of Panama. Plos One, 5(5):e10552. https://doi.org/10.1371/journal.pone.0010552

Pimiento, C. and Balk, M.A. 2015. Body-size trends of the extinct giant shark Carcharocles megalodon: a deep-time perspective on marine apex predators. Paleobiology, 41(3):479490. https://doi.org/10.1017/pab.2015.16

Purdy, R. 1996. Paleoecology of fossil white sharks, p. 67-78. In Klimley, A.P. and Ainley, D.G. (eds.), Great White Sharks: The Biology of Carcharodon carcharias. Academic Press, San Diego, California.

Purdy, R.W., Schneider, V.P., Applegate, S.P., McLellan, J.H., Meyer, R.L., and Slaughter, B.H. 2001. The Neogene sharks, rays, and bony fishes from Lee Creek Mine, Aurora, North Carolina. Smithsonian Contributions to Paleobiology, 90:71-202.

Randall, J.E. 1973. Size of the great white shark (Carcharodon). Science, 181(4095):169-170. https://doi.org/10.1126/science.181.4095.169

Razak, H. and Kocsis, L. 2018. Late Miocene Otodus (Megaselachus) megalodon from Brunei Darussalam: Body length estimation and habitat reconstruction. Neues Jahrbuch für Geologie und Paläontologie-Abhandlungen, 288(3):299-306. https://doi.org/10.1127/njgpa/2018/0743

Reolid, M. and Molina, J.M. 2015. Registro de Carcharocles megalodon en el sector oriental de la Cuenca del Guadalquivir (Mioceno superior, Sur de España). Estudios Geológicos, 71(2):e032. https://doi.org/10.3989/egeol.41828.342

Shimada, K. 2002a. The relationship between the tooth size and total body length in the white shark. Journal of Fossil Research, 35(2):28-33.

Shimada, K. 2002b. Dental homologies in lamniform sharks (Chondrichthyes: Elasmobranchii). Journal of Morphology, 251(1):38-72. https://doi.org/10.1002/jmor.1073

Shimada, K. 2005. Types of tooth sets in the fossil record of sharks, and comments on reconstructing dentitions of extinct sharks. Journal of Fossil Research, 38(2):141-145.

Shimada, K. 2019. The size of the megatooth shark, Otodus megalodon (Lamniformes: Otodontidae), revisited. Historical Biology, 1-8. https://doi.org/10.1080/08912963.2019.1666840

Shimada, K., Chandler, R.E., Lam, O.L.T., Tanaka, T., and Ward, D.J., 2017. A new elusive otodontid shark (Lamniformes: Otodontidae) from the lower Miocene, and comments on the taxonomy of otodontid genera, including the 'megatoothed' clade. Historical Biology, 29(5):704-714. https://doi.org/10.1080/08912963.2016.1236795

Shimada, K., Becker, M.A., and Griffiths, M.L. 2020. Body, jaw, and dentition lengths of macrophagous lamniform sharks, and body size evolution in Lamniformes with special reference to 'off-the-scale' gigantism of the megatooth shark, Otodus megalodon. Historical Biology, 1-17. https://doi.org/10.1080/08912963.2020.1812598

Shimada, K., Bonnan, M.F., Becker, M.A., and Griffiths, M.L. 2021. Ontogenetic growth pattern of the extinct megatooth shark Otodus megalodon-implications for its reproductive biology, development, and life expectancy. Historical Biology, 1-6. https://doi.org/10.1080/08912963.2020.1861608

Siversson, M. 2012. Lamniform sharks: 110 million years of ocean supremacy. Royal Tyrell Museum Speaker Series. Alberta, Canada. March 28, 2012. 
Tomita, T., Miyamoto, K., Kawaguchi, A., Toda, M., Oka, S.I., Nozu, R., and Sato, K. 2017. Dental ontogeny of a white shark embryo. Journal of Morphology, 278(2):215-227. https://doi.org/10.1002/jmor.20630

Trif, N., Ciobanu, R., and Codrea, V. 2016. The first record of the giant shark Otodus megalodon (Agassiz, 1835) from Romania. Brukenthal Acta Musei, 11(3):507-526.

Uyeno, T. 1989. Description of an almost complete tooth set of Carcharodon megalodon from a Middle Miocene bed in Saitama Prefecture, Japan. Bulletin of Saitama Museum of Natural History, 7:73-85.

Ward, D.J. and Bonavia, C.G. 2001. Additions to, and a review of, the Miocene shark and ray fauna of Malta. Central Mediterranean Naturalist, 3:131-146.

Welton, B.J. and Farish, R.F. 1993. The Collector's Guide to Fossil Sharks and Rays from the Cretaceous of Texas. Before Time, Lewisville, Texas.

Wintner, S.P. and Cliff, G. 1999. Age and growth determination of the white shark, Carcharodon carcharias, from the east coast of South Africa. Fish Bulletin, 97:153-169.

Zhelezko, V. and Kozlov, V. 1999. Elasmobranchii and Paleogene biostratigraphy of Transurals and Central Asia. Materials on Stratigraphy and Paleontology of the Urals, (3):1-324. 


\section{APPENDICES}

\section{APPENDIX 1.}

Crown width measurements in $\mathrm{mm}$ from modern Carcharodon carcharias $(\mathrm{n}=10)$ and Isurus oxyrinchus $(n=1)$. Measurements are separated for the different regions preserved: upper left $(U L)$, upper right (UR), lower left (LL), and lower right (LR). (All appendices are available for download in one zipped file at https://palaeo-electronica.org/content/2021/3284-estimating-lamniformbody-size.)

\section{APPENDIX 2.}

Crown height measurements in $\mathrm{mm}$ from modern Carcharodon carcharias $(\mathrm{n}=10)$ and Isurus oxyrinchus $(n=1)$. Measurements are separated for the different regions preserved: upper left $(\mathrm{UL})$, upper right (UR), lower left (LL), and lower right (LR). * pathologic or broken. (All appendices are available for download in one zipped file at https://palaeo-electronica.org/content/2021/ 3284-estimating-lamniform-body-size.)

\section{APPENDIX 3.}

Crown width measurements in mm of 11 fossil dentitions of Otodus and Carcharodon. Measurements are separated for the different regions preserved: upper left (UL), upper right (UR), lower left (LL), and lower right (LR). (All appendices are available for download in one zipped file at https://palaeo-electronica.org/content/2021/3284-estimating-lamniform-body-size.)

\section{APPENDIX 4.}

Crown height measurements in $\mathrm{mm}$ of 11 fossil dentitions of Otodus and Carcharodon. Measurements are separated for the different regions preserved: upper left (UL), upper right (UR), lower left (LL), and lower right (LR). (All appendices are available for download in one zipped file at https://palaeo-electronica.org/content/2021/3284-estimating-lamniform-body-size.)

\section{APPENDIX 5.}

Correction factors applied for missing teeth in fossil Carcharodon and Otodus dentitions. Correction factors for Carcharodon spp. are based on the mean percentage of the total summed crown width from a sample of 10 modern C. carcharias dentitions (see Figure 6A-B). Correction factors for adult Otodus megalodon are based on crown width proportions in UF-VP-311000. Correction factors for juvenile Otodus megalodon are based on crown width proportions in $\mathrm{CH}-31-46 \mathrm{P}$. Correction factors for Otodus chubutensis are from GHC 3. (All appendices are available for download in one zipped file at https://palaeo-electronica.org/content/2021/3284-estimating-lamniformbody-size.) 